\title{
A numerical model for free infragravity waves: Definition and validation at regional and global scales
}

\author{
Fabrice Ardhuin $^{\mathrm{a}, *}$, Arshad Rawat $^{\mathrm{a}, \mathrm{b}}$, Jerome Aucan $^{\mathrm{c}}$
}

\author{
a Ifremer, Laboratoire d'Océanographie Spatiale, Ifremer, Brest, France \\ ${ }^{b}$ Mauritius Oceanography Institute, Mauritius \\ c Institut de Recherche pour le Développement (IRD), Laboratoire d'Etudes en Gophysique et Ocanographie \\ Spatiale (LEGOS), Toulouse University (UPS), Toulouse, France
}

*: Corresponding author : Fabrice Ardhuin, tel.: +33298224915 ; email address : ardhuin@ifremer.fr

\begin{abstract}
:
The spectral wave model WAVEWATCH III is extended from the windsea and swell band to lower frequencies, in order to represent free waves in the infragravity (IG) wave band. This extension is based on an empirical source of IG energy, which is defined along shorelines from the significant wave height and a mean period. The empirical proportionality factor is found to reproduce accurately the variations of free IG wave energy in coastal areas, where it was calibrated, and also has a good skill at global scales. In the open ocean, the model is particularly verified for frequencies in the range 5 to $14 \mathrm{mHz}$ for which ocean bottom records are sensitive to the IG signal. The model captures between $30 \%$ and $80 \%$ of the variance in IG wave heights, depending on location, and reproduces the mean IG energies within $50 \%$. Where the model reproduces best the IG variability, it can be used to fill in the gaps between recording stations, providing a first view of the global IG wave field.
\end{abstract}

Our first application is the estimation of the surface gravity wave contribution to the surface elevation spectra that will be measured by the Surface Water Ocean Topography (SWOT) satellite mission. The actual contribution of IG waves on measured along-track wavenumber spectra varies with the crosstrack averaging method. Typically, the strongest IG signal is expected to occur for wavelengths between 2 and $10 \mathrm{~km}$. For a given region, the spectral level at $10 \mathrm{~km}$ wavelength are not very sensitive to the local depth in the range 200 to $5000 \mathrm{~m}$. At this wavelength, and on the east side of all mid-latitude ocean basins, the median spectral density associated to free IG waves is of the order of $0.4 \mathrm{~cm}^{2} /($ cycle $/ \mathrm{km})$, equal to the expected quasi-geostrophic signature of surface currents. IG spectra rise above 4 times this level for $16 \%$ of the time. Even at $20 \mathrm{~km}$ wavelength, spectral levels above $1 \mathrm{~cm}^{2} /(\mathrm{cycle} / \mathrm{km})$ are likely to occur more that $10 \%$ of the time for some oceanic regions.

\section{Highlights}

- The first global model for free infragravity (IG) waves is designed and validated. DART station measurements in deep water are well explained by the free IG model. At $20 \mathrm{~km}$ wavelength, spectral IG level above $1 \mathrm{~cm}^{2} /($ cycle/km) should occur more than $10 \%$ of the time in some regions. - Such a geophysical error is comparable to the instrument error expected for the future Karin altimeter onboard SWOT. 
Keywords: Infragravity waves ; SWOT ; Spectral model

\section{Introduction}

Infragravity (IG) waves are long period surface gravity waves which are important for nearshore or harbor hydrodynamics (e.g., Reniers et al., 2010, Okihiro et al., 1993 and Jong et al., 2003). These IG waves are expected to be generated mostly along shorelines by nonlinear interactions of the shorter wind-generated waves (e.g., Munk, 1949, Herbers et al., 1994 and Herbers et al., 1995). This interaction transfers part of the energy from the wind-generated wind sea and swells, with periods shorter than $30 \mathrm{~s}$, into sub-harmonics. For waves propagating over a flat bottom, this energy corresponds to long period oscillations traveling bound to the short wave groups but with the opposite phase. These bound components can be transformed into free waves, which then follow the linear surface gravity waves dispersion, with larger wavelengths and phase speeds. This transformation occurs where short wave energy varies rapidly, for example, in the surf zone (e.g., Henderson and Bowen, 2002). An additional source of free IG waves in the surf comes from variation of wave breaking location on the scale of wave groups (Symonds et al., 1982).

Several numerical models have been developed for IG waves in coastal areas. The underlying principles used in these models vary widely. Ruju et al. (2012) have chosen to solve for the full threedimensional hydrodynamic equations, resolving the wavelengths of the wind-waves, while Zijlema et al. (2011) have simplified the vertical structure of the flow, but still resolve the short waves. Reniers et al., 2002 and Reniers et al., 2010 have developed a cheaper method, easily applicable to larger spatial and time scales. In that latter approach, the time and length scales of wave groups are resolved, but not the scales of the short waves. Finally a wide range of spectral models with varying degrees of complexity have been developed. In these models the computation time can be further reduced because only the slow time scale of spectral evolution need to be resolved. The more complex type of spectral model includes space-time integration of both spectrum and bispectrum (e.g., Herbers and Burton, 1997). This bispectrum carries the relative phases of wave components and 
this information is necessary to compute the transformation of bound waves into free waves. Parameterizations in models that only include the spectrum have to make some assumptions on the phases, and these have not yet been able to reproduce quantitatively the IG wave generation in typical coastal areas (Toledo and Agnon, 2012). All these models have been applied with an extension along the shore that hardly exceeds $100 \mathrm{~km}$. To our knowledge, no numerical model has yet been proposed for free infragravity waves on the global scale, a problem for which existing models are not suited.

Future planned satellite missions, in particular Surface Water Ocean Topography (hereinafter SWOT, Durand et al., 2010) are targeting meso- and submeso-scale ocean circulation with horizontal scales down to $10 \mathrm{~km}$. At such scales, the estimation of surface currents from the surface elevation is expected to require an accuracy of the order of $1 \mathrm{~cm}$, which is more easily defined in terms of a spectrum. Surface quasi-geostrophic theory predicts that the spectrum of sea surface elevation decays like $k^{-11 / 3}$ towards short scales, where $k$ is the magnitude of the wavenumber vector (Lapeyre and Klein, 2006). Using this asymptote, the extrapolations from spectra at longer wavelengths (e.g. Le Traon et al., 2008) gives a current signature in surface elevation of the order of $1.9 \mathrm{~cm}^{2} /($ cycle $/ \mathrm{km})$ at a wavelength of $15 \mathrm{~km}$, and $0.4 \mathrm{~cm}^{2} /($ cycle $/ \mathrm{km})$ at a wavelength of $10 \mathrm{~km}$. It should be noted that, for this latter scale, the surface current is not completely geostrophic (e.g. Klein et al., 2009).

From an examination of tsunami warning (DART) stations, Aucan and Ardhuin (2013) have found that in $3.3 \mathrm{~km}$ depth off the Oregon coast the spectral level of $0.5 \mathrm{~cm}^{2} /($ cycle $/ \mathrm{km})$ at a wavelength of $15 \mathrm{~km}$ is exceeded $15 \%$ of the time due to infragravity waves alone, decreasing to $0.35 \mathrm{~cm}^{2} /(\mathrm{cycle} / \mathrm{km})$ at a wavelength of $10 \mathrm{~km}$ (Aucan and Ardhuin, 2013). As we show below, these spectral level estimates were underestimated by a factor of two.

With a typical wavenumber slope ranging from -0.5 to -1 , much shallower than the $-11 / 3$ slope expected for submesoscale currents, it appears likely that there is a scale, somewhere between 2 and $20 \mathrm{~km}$, below which the infragravity signal will often exceed the signal of submesoscale currents. Hence, the routine processing of future SWOT data may well require some model of the global IG wave field, in order to flag the locations and times when resolution may be degraded by energetic IG waves. Indeed, contrary to the atmospheric corrections measured separately and the coherent part of the barotropic and internal tides, the random nature of the IG wave phases makes it impossible to correct for associated sea level variations, in the ab- 
sence of a dense network of observations, or the measurement of the IG wave propagation during the time of integration of the radar. However, the surface elevation variance caused by IG waves is predictable, as we will show here.

Our objective is thus twofold. First, we want to confirm that the signal recorded by DART stations is consistent with plausible IG wave sources and dynamics at frequencies between 5 and $14 \mathrm{mHz}$. Second, we wish to extrapolate the measurements from the DART network beyond their spatial and spectral coverage. Both tasks require the development of a numerical model for free IG waves. This model may prove useful for the analysis of high resolution surface currents from the SWOT mission. It will also allow an estimation of the debated location and magnitude of seismic hum sources (see e.g. Rhie and Romanowicz, 2006).

This paper presents the first attempt at building such a model for the global ocean. Similar to early numerical models for ocean waves, this is a 'first generation model' in the sense that the source of free IG energy at the coast is parameterized from integrated wave parameters. The rationale for treating free IG waves only is that, for depths larger than about $50 \mathrm{~m}$, these generally dominate the recorded signal, compared to bound components (Herbers et al., 1995b; Webb et al., 1991). Besides, the bound components can be obtained from the local wave spectrum assuming a flat bottom, in the case of intermediate or deep water (Creamer et al., 1989; Herbers et al., 1992; Janssen, 2009).

Here we focus on waves with periods between 30 and $200 \mathrm{~s}$. This choice is motivated by the fact that an IG period of $200 \mathrm{~s}$ already gives wavelengths larger than $15 \mathrm{~km}$ in water depths greater $600 \mathrm{~m}$, consistent with our interest in the surface elevation spectrum around $10 \mathrm{~km}$ wavelength, with a priority on the deep ocean. Also, these longer waves are less dispersive and one may infer the properties of $500 \mathrm{~s}$ waves from those of $200 \mathrm{~s}$ waves, assuming a simple relation at the source between these two components. Contrary to the existing models that reproduce IG waves in coastal regions, we consider here a very crude approximation of the IG wave evolution in shallow water, in order to cover the global ocean. For this we present a parameterization of the free IG source at the shoreline, in section 2. The accuracy of the model in terms of propagation in regional and global configurations is discussed in section 3. Implications of modeled IG spectra in the context of SWOT are discussed in section 4 , and conclusions follow in section 5 . 


\section{The nearshore source of free infragravity waves: observations and parameterizations}

Among the infragravity waves, it is important to distinguish the bound and free waves. Both are surface gravity waves with a vertical scale of attenuation of the motion that is proportional to their wavelength, but their wavelength can be very different for the same wave period. Namely, free waves follow the dispersion relation of linear waves (de Laplace, 1776), while bound waves have a wavelength defined by the forcing. Because bound waves are negligible in the open ocean (Herbers et al., 1995b) and can be predicted from the local sea state, we will only model the free infragravity waves. When comparing model results to measurements, we must be careful that bound components can have a significant contributions to measured pressure time series in shallow water. Herbers et al. (1994) showed that the bound part of the IG spectrum can be estimated with a bi-spectral analysis where both short waves and long waves are resolved in the measurements. This technique was already applied to the DUCK94 dataset by Evangelidis (1996) who concluded that the bound fraction of the IG bottom pressure variance is typically less than $20 \%$ for this dataset, with the highest fractions found during the most energetic wind-wave conditions. The free wave spectrum may further be decomposed into trapped and leaky modes (e.g. Herbers et al., 1995a). The trapped modes are confined to continental shelves due to their refraction. The leaky modes, with propagation direction nearly perpendicular to the depth contours, are able to escape to deep water then travel across Oceans. Our model considers both trapped and leaky modes.

Because we cannot afford the spatial resolution required to solve for the non-linear phase-dependent evolution of the wave field on the scale of the few wavelengths closest to shore, we have sought to parameterize the nearshore source of free IG waves as a function of the short wave spectrum.

This source is introduced in the version 4.18 of the spectral wave model WAVEWATCH III, hereinafter WW3 (Tolman, 2008), in the subroutine that computes the equivalent source term corresponding to shoreline reflection. The following algorithm is used. First we compute an 'equilibrium' free infragravity wave spectrum $E_{I G}(f, \theta)$ from the incoming short wave spectrum, as detailed below. Second, for a specified IG frequency band, here 0.003 to $0.03 \mathrm{~Hz}$, the spectrum at the boundary is overwritten with this IG spectrum. This procedure introduces a discontinuity between the specified IG band, for which the spectral level is imposed at the shorelines, and the rest of the 
spectrum for which the spectrum level is the result of an energy balance between sources and sinks. An alternative formulation of the free IG source as a usual source term, namely a rate of transfer of energy per unit time, is still under development for the IG band, but we use it to provide free IG energy at frequencies above those of the IG band, allowing a smooth overlap between short IG waves and long swells. The over-writing of the boundary spectrum follows the numerical approach already used for shoreline reflection by Ardhuin and Roland (2012).

Initially, we tried to formulate $E_{I G}(f, \theta)$ from the second order spectrum solution over a flat bottom, but it has proved difficult to mimic with simple rules the complex spectral evolution of waves in shallow water. As a temporary solution, we have sought an empirical parameterization from the short wave spectrum. Herbers et al. (1995b) previously showed that free IG wave height $H_{I G}$ is very much related to the wind sea and swell height $H_{s}$. This relationship between $H_{I G}$ and $H_{s}$ varied from site to site, with a clear effect of the water depth, and possibly an effect of the bottom slope. In a recent analysis of IG data measured around New Zealand, Godin et al. (2013) confirmed this depth variation, and also provided a parameterization of the IG frequency spectra as a function of depth alone, i.e. not considering the variability of the IG spectrum with short wave parameters such as $H_{s}$. Here, we first parameterize $H_{I G}$ from $H_{s}$, depth, and a mean short wave period, then we propose a form for the frequency-direction spectrum $E_{I G}(f, \theta)$.

For this purpose we have used data from three different sites, the North Carolina shelf (experiment DUCK94, see Evangelidis, 1996; Herbers et al., 1999), Waimea on the Oahu North shore (Hawaii) with a dedicated bottom pressure recorder deployment in 2012, and three French Atlantic sites, off Crozon in $100 \mathrm{~m}$ depth, in the middle of the small Bertheaume bay in $23 \mathrm{~m}$ depth (Guyonic et al., 2007), and at the foot of the steep western cliff of the island of Banneg (Fichaut and Suanez, 2011; Ardhuin et al., 2011a; Sheremet et al., 2014). In the last case we have only kept high tide measurements, with water levels above $5 \mathrm{~m}$, and data for which the $H_{s}$ to water depth ratio is less than 0.3 . That latter constraint limits the contamination from bound waves. The main characteristics of the records used are listed in table 1 .

Interestingly, looking at DART stations off the U.S. West coast, the infragravity energy is still well correlated with local short wave parameters. Taking the DART station 46407, in $3300 \mathrm{~m}$ depth off the Oregon coast, half of the variance $(r=0.67)$ in the $\mathrm{IG}$ wave height is explained by local short 
Table 1: Characteristics of pressure records used in the present paper. The correlations given here are based on time series sampled every 3 hours, using eq. (3) with sea state parameters $H_{s}$ and $T_{m 0,-2}$ measured at the same location as the infragravity wave height $H_{I G}$ defined by eq. (1). In the case of DART station 46407 , located $500 \mathrm{~km}$ from the Oregon coast, we have used the wave data from the surface buoy number 46002, located within $15 \mathrm{~km}$, and provided by the National Data Buoy Center. For that station, we extrapolated the recorded IG spectrum from $0.14 \mathrm{~Hz}$ to $0.3 \mathrm{~Hz}$ in order to estimate the empirical coefficient $\alpha_{1}$ that is defined by eq. (5).

\begin{tabular}{llllll}
\hline Location & depth & start date & duration & $\alpha_{1}\left(\mathrm{~s}^{-1}\right)$ & correlation $(\mathrm{r})$ \\
\hline A (Duck, NC) & $12 \mathrm{~m}$ & $1994 / 09 / 10$ & 100 days & $8.1 \times 10^{-4}$ & 0.97 \\
F (Duck, NC) & $33 \mathrm{~m}$ & $1994 / 09 / 10$ & 100 days & $4.6 \times 10^{-4}$ & 0.97 \\
H (Duck, NC) & $50 \mathrm{~m}$ & $1994 / 09 / 10$ & 100 days & $4.0 \times 10^{-4}$ & 0.97 \\
I (Duck, NC) & $87 \mathrm{~m}$ & $1994 / 09 / 10$ & 100 days & $4.0 \times 10^{-4}$ & 0.96 \\
51201 (Waimea, HI) & $165 \mathrm{~m}$ & $2012 / 01 / 18$ & 100 days & $5.3 \times 10^{-4}$ & 0.95 \\
Crozon (France) & $110 \mathrm{~m}$ & $2011 / 09 / 10$ & 15 days & $7.9 \times 10^{-4}$ & 0.86 \\
Bertheaume (France) & $23 \mathrm{~m}$ & $2004 / 01 / 19$ & 104 days & $4.4 \times 10^{-4}$ & 0.88 \\
Banneg island (France) & $5 \mathrm{~m}$ & $2009 / 12 / 03$ & 89 days & $5.0 \times 10^{-4}$ & 0.85 \\
DART 46407 & $3266 \mathrm{~m}$ & $2008 / 01 / 01$ & 366 days & $5 \times 10^{-4}$ & (with lag: 0.89) \\
\hline
\end{tabular}

waves present at the same time. The correlation increases to $r=0.89$ when $H_{I G}$ is taken 10 hours after the short waves. This strong correlation is explained by the relatively short distance, about $500 \mathrm{~km}$, between the DART station and a stretch of shoreline that is one of the strongest sources in the Pacific. We expect that the IG waves recorded at 46407 are generated on the Oregon shore by waves that hit the shoreline, 10 hours after having travelled over the DART instrumentation. This time difference is the time necessary for wave energy with a period of $18 \mathrm{~s}$ to travel from the short-wave measuring buoy, NDBC buoy number 46002, and the shoreline. The travel time of IG waves in the opposite direction is expected to be only one hour. Correlations with local sea states are much weaker at West Pacific DART stations, suggesting that nearby coastal sources are less important than remote sources.

We define the infragravity wave height from the surface elevation spectrum as

$$
H_{I G}=4 \sqrt{\int_{0.005 \mathrm{~Hz}}^{0.03 \mathrm{~Hz}} E(f) \mathrm{d} f} .
$$

In practice, the surface elevation spectrum was estimated from measured bottom pressure spectrum $F_{p}(f)$, assuming linear wave theory which is only 
valid for the free wave components,

$$
E(f)=\frac{=F_{p}(f)}{\left[\rho_{w} g \cosh (k D)\right]^{2}} .
$$

For the other datasets we have estimated the bound energy level in bottom pressure records by applying the second order theory (Biesel, 1952; Herbers et al., 1992) to frequency-directional spectra given by either numerical wave models or surface buoy data processed with the Maximum Entropy Method (Lygre and Krogstad, 1986). In $165 \mathrm{~m}$ depth at Waimea, this bound energy estimated from the buoy contributes less than $0.1 \%$ of the bottom pressure variance in the IG frequency band. We have thus assumed that the bottom pressure recorded at Waimea and Crozon was only due to free wave components.

The analysis of measured bottom pressure spectra reveals a strong correlation between the infragravity wave height and integral wave parameters. From the examination of all three datasets, we conclude that $H_{I G}$ increases with an increase in wave height and wave period. Several combinations and different definitions of the mean period parameter give a significant correlation. However, in particular for the Waimea data, we have found a large correlation using

$$
H_{I G} \simeq \alpha_{1} H_{s} T_{m 0,-2}^{2} \sqrt{g / D}
$$

where $\alpha_{1}$ is a dimensional coefficient that varies from one site to another, $g$ is the apparent acceleration of gravity and $D$ is the mean water depth (see table 1 ). The mean period is defined as $T_{m 0,-2}=\sqrt{m_{-2} / m_{0}}$ with the moments

$$
m_{n}=\int_{0.03 \mathrm{~Hz}}^{0.5 \mathrm{~Hz}} E(f) f^{n} \mathrm{~d} f \text {. }
$$

The fit given by eq. (3) is illustrated in figure 1, with two coastal sites in North Carolina and Hawaii. It is interesting to note that the linear dependence $H_{I G} \propto H_{s}$ was already observed by Tucker (1950), and is consistent with all the datasets reported in Herbers et al. (1995b).

The slightly better fit obtained with the mean period $T_{m 0,-2}$ compared to the more usual $T_{m 0,-1}$ or peak period $T_{p}$ can be explained by the fact that it is really the peak of the spectrum that matters, and $T_{m 0,-1}$ can be sometimes modified by the presence of high-frequency energy, while $T_{p}$ is intrinsically a very noisy parameter (Young, 1995). 

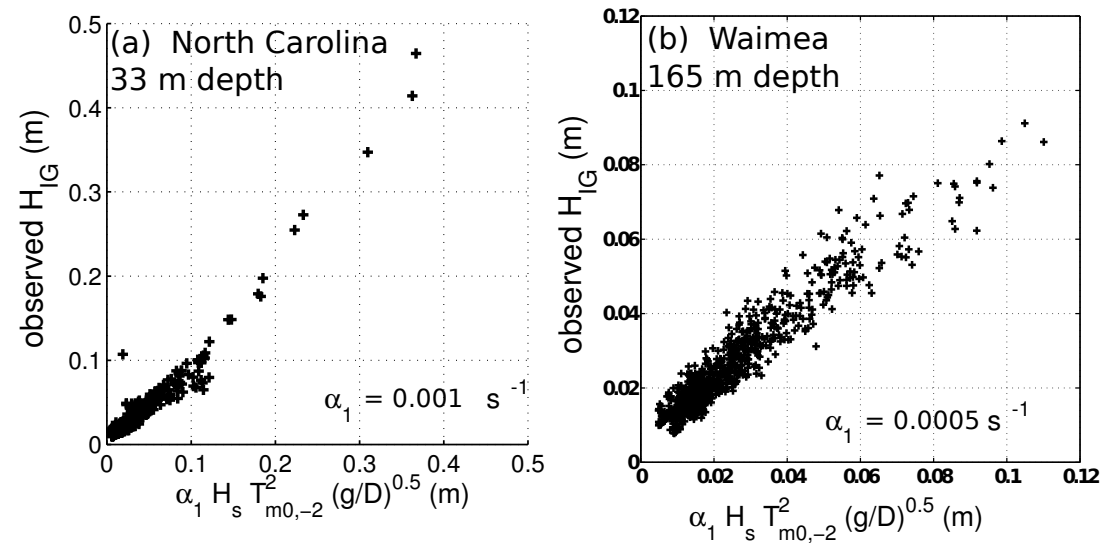

Figure 1: Measured and parameterized infragravity wave heights at two sites off (a) North Carolina and (b) Hawaii. The measured $H_{I G}$ is compared to the local value of the product $\alpha_{1} H_{s} T_{m 0,-2}^{2} \sqrt{g / D}$ where $\alpha_{1}$ is a locally adjusted parameter.

Another possible relevant parameter is the spectral peakedness which defines the narrowness of the frequency spectrum (e.g. Saulnier et al., 2011). We have tested different definition of the peakedness but found only a marginal improvement in the correlation. This may be because the peakedness is correlated with the wave period, already taken into account, because long period swells have more often a narrow spectrum.

Given that the parameterized IG source will be put in the numerical wave model at all points adjacent to the land, where the depth may have any value, we have adjusted eq. (3) to reproduce the expected shoaling of a broad directional wave spectrum, adjusting the factor $g / D$ for each frequency $f$ to $F=k g^{2} /\left(C_{g} 2 \pi f\right)$. The term $2 \pi k / C_{g}$ is the Jacobian of the coordinate transform from wavenumber vectors $\left(k_{x}, k_{y}\right)$ to frequency and direction. This term accounts for the conservation of energy with changing water depths, which also corresponds to a conservation of the spectral density $E\left(k_{x}, k_{y}\right)$, as established by Longuet-Higgins (1957), and used by Herbers et al. (1995a). The other part of the $F$ factor, namely $g^{2} /\left(4 \pi^{2} f\right)$ is constant during the wave evolution. $F$ takes the limit $g / D$ given by Herbers et al. (1995b) when the non-dimensional $k D$ goes to zero, and typically yields larger values for finite values of $k D$. We have thus replaced the right-hand side of (3) with the the parameterized value $\widehat{H}_{I G}$ given by eq. (8).

We have estimated the empirical coefficient $\alpha_{1}$ from each data set by 
minimizing the mean error in predictions of IG wave heights using eq. (3). From the Waimea data, in $165 \mathrm{~m}$ depth, we estimated $\alpha_{1}=5 \times 10^{-4} \mathrm{~s}^{-1}$, while the DUCK94 dataset gives $\alpha_{1}$ ranging from 8 to $11 \times 10^{-4} \mathrm{~s}^{-1}$, and the French coastal data gives 4.4 to $8 \times 10^{-4} \mathrm{~s}^{-1}$. For each dataset the correlation ranges from 0.85 to 0.98 (see Table 1 ). In other words, a large part of the free IG energy variations is caused by the short wave energy and period, and the local depth. This is broadly consistent with the analysis of several locations in Hawaii, California and North Carolina by Herbers et al. (1995b). These authors also suggest that the shelf width can be an important factor, which may be the reason for the different values of $\alpha_{1}$. Overall, there is much less scatter than in regressions of wind-wave parameters against wind speed and fetch (e.g. Kahma and Calkoen, 1992), which points to a very strong control of the local sea state on the free IG spectrum in coastal areas. The correlations are still significant at DART stations located a few hundreds of kilometers from the U.S. West coast, but they decrease to $\mathrm{r}<0.5$ as we cross the Pacific to the West, suggesting that, in the deep waters of the West Pacific, the nearby East-Asian coastal sources are often dwarfed by remote IG sources, mostly from the U.S. Pacific Northwest according to our model.

We have also inspected the shape of IG wave spectra and attempted to reproduce them. These spectra are relatively flat in the shallow waters of the North Carolina shelf, for frequencies between 10 and $30 \mathrm{mHz}$, rolling off towards lower and higher frequencies (Evangelidis, 1996). In the 90 to $150 \mathrm{~m}$ water depths at Waimea, Crozon or on the shelf break at Duck, $E(f)$ generally increases by about $50 \%$ from 5 to $15 \mathrm{mHz}$ and decreases as $1 / f$ up to $30 \mathrm{mHz}$. For $3000 \mathrm{~m}$ depth or more, the bottom pressure records can only measure up to $12 \mathrm{mHz}$, and are consistent with an increase in energy level in that frequency range.

Finally we also need to parameterize the directional distribution of IG wave energy. Nearshore measurements have revealed broad directional IG spectra with a clear asymmetry between the two alongshore directions as a function of the incident swell directions (Herbers et al., 1995b, their figure 6 ). Here we have taken a very crude first approximation by making the IG wave spectrum isotropic in directions at the first wet node of the model.

As a result, our empirical parameterization of the IG wave source takes following form,

$$
A_{I G}=H_{s} T_{m 0,-2}^{2}
$$




$$
\begin{aligned}
E_{I G}(f) & =1.2 \alpha_{1}^{2} \frac{k g^{2}}{C_{g} 2 \pi f} \frac{\left(A_{I G} / 4\right)^{2}}{\Delta_{f}}[\min (1 ., 0.015 \mathrm{~Hz} / f)]^{1.5} \\
E_{I G}(f, \theta) & =E_{I G}(f) /(2 \pi)
\end{aligned}
$$

where we have used $\alpha_{1}=6 \times 10^{-4} \mathrm{~s}^{-1}$ and $\Delta_{f}=0.0279 \mathrm{~Hz}$. As explained above, the $k / C_{g}$ factor accounts for the shoaling of a broad directional spectrum, while the frequency shape of the spectrum is given by the other terms. In the shallow water limit, i.e. $k D$ going to zero, the spectrum is constant up to $f=15 \mathrm{mHz}$ and decreases like $f^{-1.5}$ for higher frequencies. In that frequency range, this asymptote is identical to the form $\tanh (k D)^{-1.5}$ given by Godin et al. (2013). The differences at lower frequencies may be due to the fact that, in particular for $f<2 \mathrm{mHz}$, the measured wave field in the open ocean is mostly driven by atmospheric pressure and not IG waves radiated from shorelines (Filloux, 1980; de Jong et al., 2003).

Eq. (7) gives an estimate $\widehat{H}_{I G}$ of the infragravity wave height,

$$
H_{I G}=\int_{0.05 \mathrm{mHz}}^{30 \mathrm{mHz}} \widehat{E}_{I G}(f) .
$$

We repeat that this spectrum $E_{I G}(f, \theta)$ replaces the reflected wave components in the IG band at the first wet nodes next to land. At higher frequencies, the free IG source is reduced by a factor 4 and added to the reflection from remote sources, with a reflection coefficient of the energy defined from a constant shoreface slope of 0.1 (Ardhuin and Roland, 2012) and a limited to a maximum reflection coefficient of 0.8 . In the IG band, this treatment may underestimate the free IG energy close to shore in very low swell conditions since we will not have the multiple shoreline reflections of remote sources (Herbers et al., 1995b). Finally, our numerical implementation gives a very large importance to the depth of these first wet nodes. In the present paper, we apply these parameterizations in model grids where the surf zone is generally not resolved. In practice this suggests to use a model grid in which the depths along the coast are carefully defined. Here we make sure that the first wet nodes have a depth of at least $3 \mathrm{~m}$ in the case of the North Carolina shelf, and $10 \mathrm{~m}$ for the global grid.

\section{Numerical implementation and validation in coastal areas}

Given the very high correlation of coastal IG wave energy with the product $H_{s} T_{m 0,-2}^{2}$, a numerical model that accurately predicts $H_{s}$ and $T_{m 0,-2}$ 
should be able to give a reliable estimate of $H_{I G}$ in coastal areas dominated by local sources. The data analysed in the previous section suggests that the empirical coefficient $\alpha_{1}$ in eq. (5) may vary by a factor 2 , but this may also be the result of a variation of $H_{s}$ and $T_{m 0,-2}$ between the IG observation point and the IG generation region. This may require a re-calibration of the value of $\alpha_{1}$. We now need to test this hypothesis numerically.

A first problem to overcome is the accuracy of the propagation scheme. Ray-tracing is an accurate method to solve the energy balance equation in the geometrical optics approximation, but we instead embed our IG source into WW3, in order to benefit from its accuracy for wind seas and swell parameters (e.g. Rascle and Ardhuin, 2013). The finite-difference schemes in this type of model can introduce some distortions on the wave energy field. We have thus first verified that the combinations of the Ultimate QUICKEST advection scheme (Leonard, 1991) for refraction together with either the same scheme used for regular grids, or the N-scheme used for triangle-based meshes (Csík et al., 2002; Roland, 2008), do produce a proper attenuation of the IG wave energy away from a shoreline. This aspect is detailed in the Appendix. Here we do not take into account diffraction effects which may be important for wave propagation perpendicular to depth contours (Thomson et al., 2005), but which were found to be small for oblique propagations (Magne et al., 2007).

In all our applications, WW3 is set-up with a spectral discretization over 53 frequencies exponentially spaced from 0.005 to $0.72 \mathrm{~Hz}$, and 24 directions for the regional grids or 36 directions for the global grid. All model configurations are forced by ECMWF operational analysis winds, together with sea ice concentration from the ECMWF analyses and small icebergs analysed by Ifremer/CERSAT (Ardhuin et al., 2011b; Tournadre et al., 2012). These latter two forcing fields are only relevant for the global model. The coastal grids are nested off-line in a multi-grid system that includes a 0.5 degree global grid and two 1/6 degree East Pacific and West Atlantic grids (Rascle and Ardhuin, 2013).

The parameterizations used for wave evolution combine the wind-wave growth and dissipation parameterization described in Ardhuin et al. (2010) and the SHOWEX bottom friction term (Ardhuin et al., 2003a), which takes into account the formation of sand ripples on the bottom (Ardhuin et al., 2002). The sediment cover was represented with a uniform median grain size of $0.2 \mathrm{~mm}$ which is particularly well suited for the North Carolina shelf. For the Hawaii case, bottom friction has little influence on the wave heights 
recorded at the Waimea buoy, and we keep the same bottom friction parameterization.

\subsection{A narrow shelf: Oahu's north shore, Hawaii}

We use the 10000-node mesh of the Hawaiian islands built by Ardhuin and Roland (2012), based on bathymetry assembled by the Hawaii Mapping Research Group. In the present calculation, the nodes with water depths less than $4 \mathrm{~m}$ were excluded and considered land, and the IG wave source is introduced at the first wet nodes next to the land nodes. No incoming IG energy is imposed at the offshore boundary, so that the IG energy in our simulations is only coming from the Hawaiian islands where it is introduced based on eqs. (5)-(7) using $\alpha_{1}=10 \times 10^{-4} \mathrm{~s}^{-1}$.

A typical IG field from a north-west swell event is shown in figure 2. The nearshore IG levels decay rapidly from about $30 \mathrm{~cm}$ in $4 \mathrm{~m}$ depth to $2 \mathrm{~cm}$ in $4000 \mathrm{~m}$ depth. Close to shore, this decay is consistent with eq. (5), which is only valid for a straight shoreline. Further away, an additional reduction proportional to the inverse of the distance is associated to the lateral spreading of the IG wave fronts far away from the islands. This decrease of the IG wave field corresponds to the conservation of the energy flux away from a localized source.

Short wave parameters are well estimated by the wave model away from the islands, with typical errors on $H_{s}$ of the order of $10 \%$ and less for the mean periods (Rascle and Ardhuin, 2013; Ardhuin et al., 2013). However, the model is less accurate closer to coast, with errors of the order of $20 \%$ for $H_{s}$, as shown in figure 3. Given these errors and the strong correlation between $H_{I G}$ and $H_{s}$, it is not surprising that the correlation between the modelled and observed values of $H_{I G}(r=0.93)$ is less that the correlation with the measured $H_{s}$. However, the weak bias on $H_{I G}$, obtained with $\alpha_{1}$ only $20 \%$ larger than the value estimated from the data, confirms that our modeling approach is sound. The times when the model errors are largest for $H_{I G}$ can be clearly associated to large errors on $H_{s}$, for example on March 5 and 6.

Figure 3.b illustrates how $H_{I G}$ increases with the mean wave period. For example, the highest values of $H_{I G}$ are recorded on January 31st, which corresponds to the largest mean period, but not the largest wave height. Also, on March 9, the increase in $H_{s}$ from the previous day is more than compensated by a drop in mean period from 12 to $8 \mathrm{~s}$. 

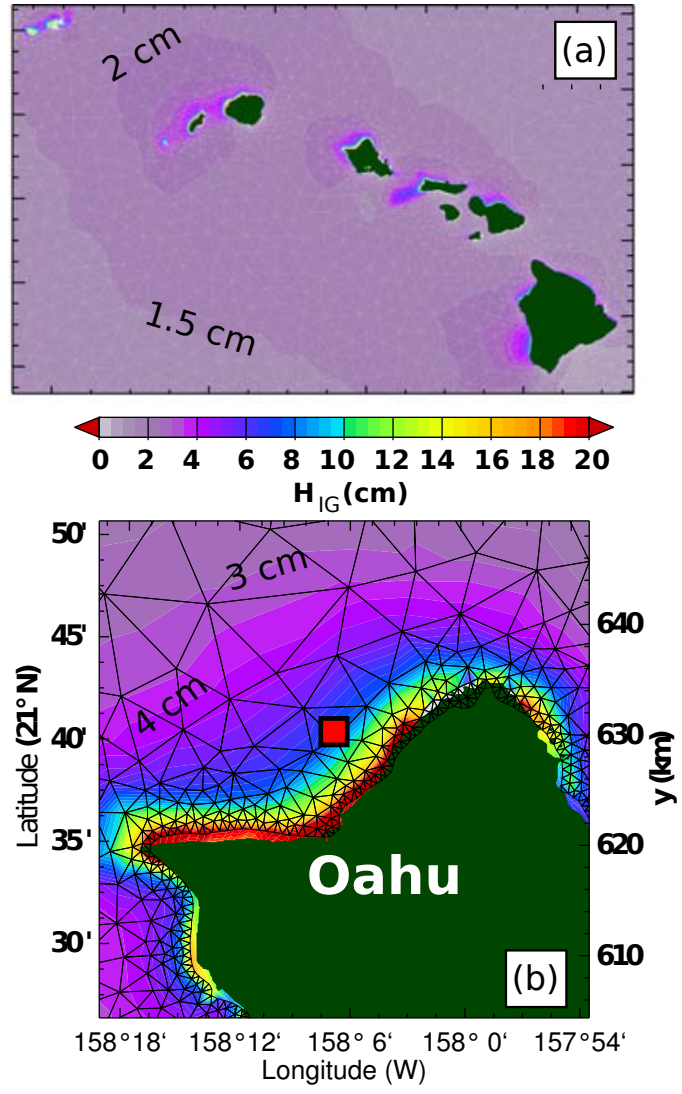

Figure 2: Modelled IG wave heights on January 31, 2012 at 0 UTC. (a) Snapshot of modelled $H_{I G}$ around all the islands, and (b) close-up in the Oahu north shore, where the Waimea buoy and mooring were located (red square).

Because free IG waves arriving at the Waimea buoy come from sources along the Oahu north shore, where wave energy levels and wave periods are strongly correlated, it behaves as if the free IG energy is coming from a single source. As a result, this data alone is not very useful for verifying the relative magnitude of different coastal sources or propagation effects on the scale of an ocean basin. A new experiment is under way with two bottom pressure sensors located further away from the island. This should provide information on how this locally-generated IG field may, at times, be dominated by a Pacific-wide IG wave field. 

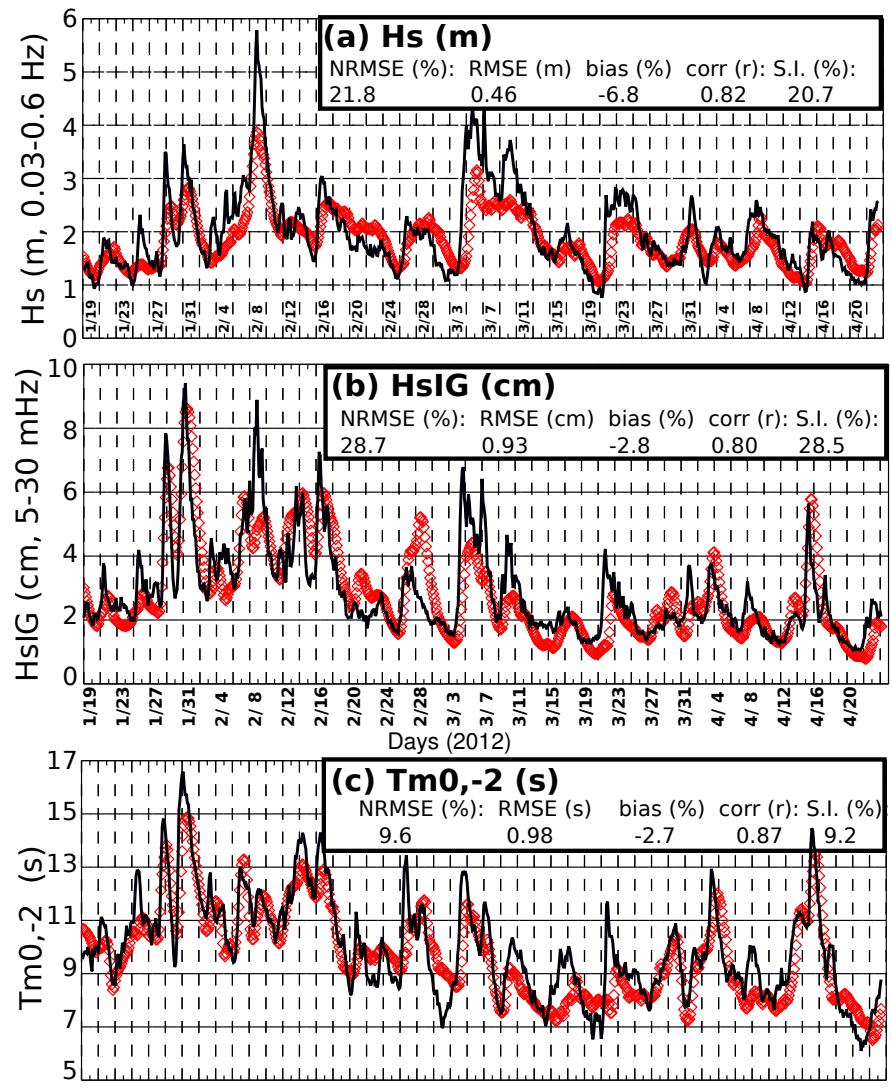

Figure 3: Measured (solid lines) and modelled (symbols) wave parameters for Waimea, Hawaii. (a) Wave heights, (b) infragravity wave heights, (c) mean period. The dates are written below panel (b), every four days only, starting on January 19, 2012.

\subsection{A wide shelf: North Carolina}

The North Carolina - Virginia shelf was represented with a regular grid, with a resolution of 1/60 degree, previously used in Ardhuin et al. (2007, 2010). Bottom friction plays an important role for swells in this region (Herbers et al., 2000; Ardhuin et al., 2001, 2003b), but the effect of bottom friction on infragravity waves is poorly known. Evangelidis (1996) analysed the DUCK'94 experiment data, separating the recorded infragravity signal into bound and free parts. He found that the free energy decreases faster towards deep water in the presence of larger swells, suggesting a stronger dissipation of free IG energy during heavy swells. However, no parameterization 
of bottom friction has ever been tested for free infragravity wave energy.

We have thus made three different model runs. In run BT0, the bottom friction was set to zero for both the swell and IG bands. In run BT4, the SHOWEX parameterization was applied all across the spectrum, including the IG band. Finally, in run BT4IG0, the SHOWEX parameterization was applied only to the swell band, and no friction was applied to the IG band. For all three models, the free IG source is parameterized with eq. (6), with the same empirical factor $\alpha_{1}$. However, that factor has been increased from the $1 \times 10^{-3} \mathrm{~s}^{-1}$ suggested by the data analysis in section 2 , to $2.5 \times 10^{-3} \mathrm{~s}^{-1}$. This increase probably compensates for the important dissipation of IG waves on the inner shelf, as discussed below, but also possibly for the limited alongshore extent of the model domain, with a missing source of IG waves trapped as edge waves that should otherwise come from the regions located north and south of our model domain.

All three model runs are very close in terms of swells near the shelf break and agree well with observations. From August $1^{\text {st }}$ to November $15^{\text {th }}$, the model results have a normalized r.m.s. error (NRMSE) of $18 \%$ at the buoy 44014 located in $50 \mathrm{~m}$ depth which includes a $10 \%$ relative bias, and a $7 \%$ NRMSE for the mean period $T_{m 0,-2}$ with a bias under $1 \%$. The BT0 model run differs at the shallow sensors, and a better fit and lower bias was obtained with BT4 and BT4IG0, consistent with the results of Ardhuin et al. (2001, 2003b).

In terms of IG wave energy, the three models give fairly different results, as illustrated by figure 4 . The time series show a large swell event, around October 17, already analysed in Ardhuin et al. (2001). Although the BT4 simulation performs well in terms of swell, it produces a much lower IG wave height than BT4IG0, showing that, in the model, bottom friction has a very strong impact on the IG wave energy balance when the IG wave energy and swell are treated together in the same parameterization. Given our model hypotheses, it is not clear how real that effect is. Indeed, it is well known that it makes little sense to treat motions that have very different time scales with the same bottom friction parameters (e.g. Grant and Madsen, 1979), and each of these motions has a different boundary layer thickness. The better result obtained with the lower friction in BT4IG0 may come from compensating errors. In their model, Reniers et al. (2002) needed a friction for the IG motion that was compatible with the friction for longshore currents, in order to balance the constant source of IG energy. Their friction is a linear function of the short wave agitation and the IG wave velocity, in 

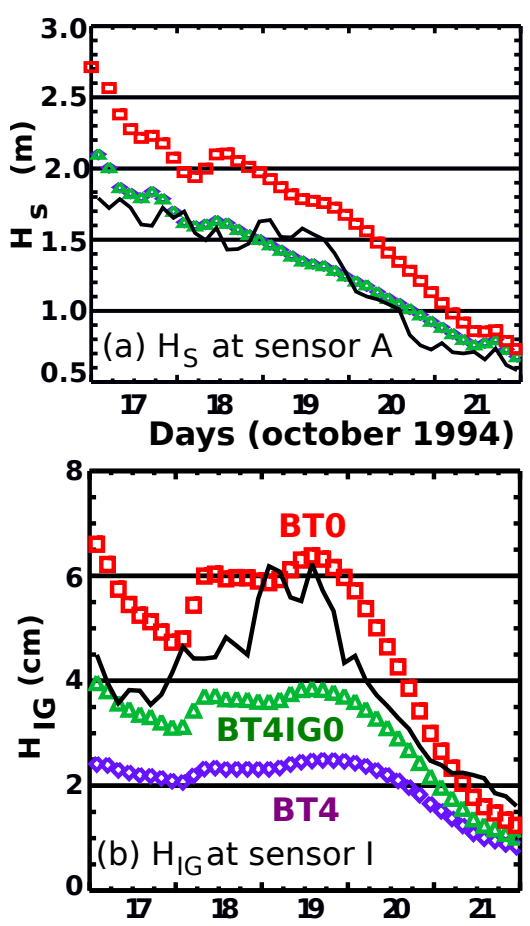

Figure 4: Measured (solid lines) and modelled (symbols) (a) wave heights in $12 \mathrm{~m}$ depth at sensor $A$, just offshore of the Field Research Facility at Duck, NC, and (b) IG wave heights in 49 meter depth at the sensor $H$, located near NDBC buoy 44014, close to the shelf break. The model runs BT0 has no bottom friction, while a SHOWEX bottom friction is applied to the full spectral range in BT4 and the wind sea and swell only in BT4IG0.

a way similar to our spectral source term. In our case, the prescribed free IG energy level at the shoreline, with no influence of the incoming free IG energy, may not be very realistic and may require unrealistically low friction to produce good results. In the end, with our form of the shoreline boundary condition, acceptable results across the North Carolina shelf are obtained without friction in the IG band, and $\alpha_{1} \simeq 2.5 \times 10^{-3} \mathrm{~s}^{-1}$, or by including the IG band in the SHOWEX bottom friction but $\alpha_{1} \simeq 4 \times 10^{-3} \mathrm{~s}^{-1}$. These values are significantly different from the Hawaii case, and further investigations will be required using models that explicitly describe the interactions of short waves and IG waves. 


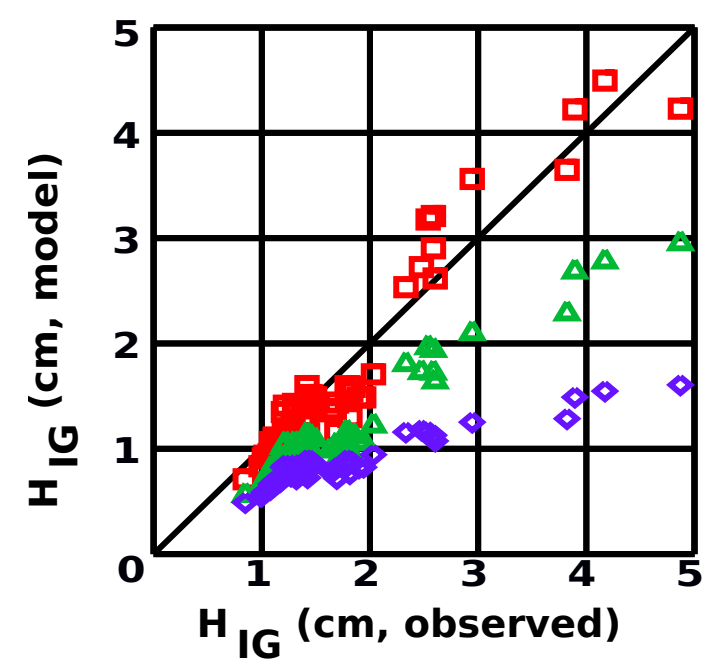

Figure 5: Quantile-quantile distribution of IG wave heights for sensor $I$ deployed during the DUCK'94 experiment compared to three model runs that use different bottom friction parameterizations. For each run, a symbol corresponds to a percentile of the modelled and measured IG wave heights over the full experiment period. From top to bottom the model runs are BT0, BT4IG0 and BT4, all use the same free IG source parameterization at the shoreline, with $\alpha_{1}=2.5 \times 10^{-3} \mathrm{~s}^{-1}$. Here the measured IG wave height contains both free and bound components, while the model represents only the free waves. However, at this location, the bound wave are found to account only for a small fraction of the IG energy (Evangelidis, 1996). Correlation of time series at 3 hour intervals, vary from $r=0.68$ for BT4 to, $r=0.79$ for BT4IG0, which is comparable to the $r=0.82$ obtained for wind sea and swell height.

\subsection{Model evaluation for the global ocean}

For the global ocean we use a single global grid with a resolution of 0.5 degree. This configuration has a performance for wind seas and swells which is very close to the multi-grid system validated in detail by Rascle and Ardhuin (2013). The IG source was computed for all shorelines, including subgrid islands, with a constant $\alpha_{1}=1 \times 10^{-3} \mathrm{~s}^{-1}$. This value is identical to the one used for the Hawaii regional model, and lower than the one giving best results for the North Carolina shelf. The results described below are based on gridded output at three-hourly intervals, as well as directional spectra for many locations, that are all available in NetCDF format at the following URL: http://tinyurl.com/iowagaftp/HINDCAST/OTHER_RUNS. 


\subsection{Infragravity wave heights}

As expected, the modelled global IG wave field is most energetic on continental shelves, especially on wide shelves of exposed coasts, including north-west Europe or the southern Australian bight. Figure 6 shows the average value of $H_{I G}$ for typical northern hemisphere winter and summer months, with a clear seasonality given by the seasonality of swells. Storm waves in the winter of each hemisphere give higher infragravity wave heights. Where we have data, these pattern are consistent with records from Deepocean Assessment and Reporting of Tsunamis (DART) systems analysed by Aucan and Ardhuin (2013). Each ocean basin is dominated by a few local-

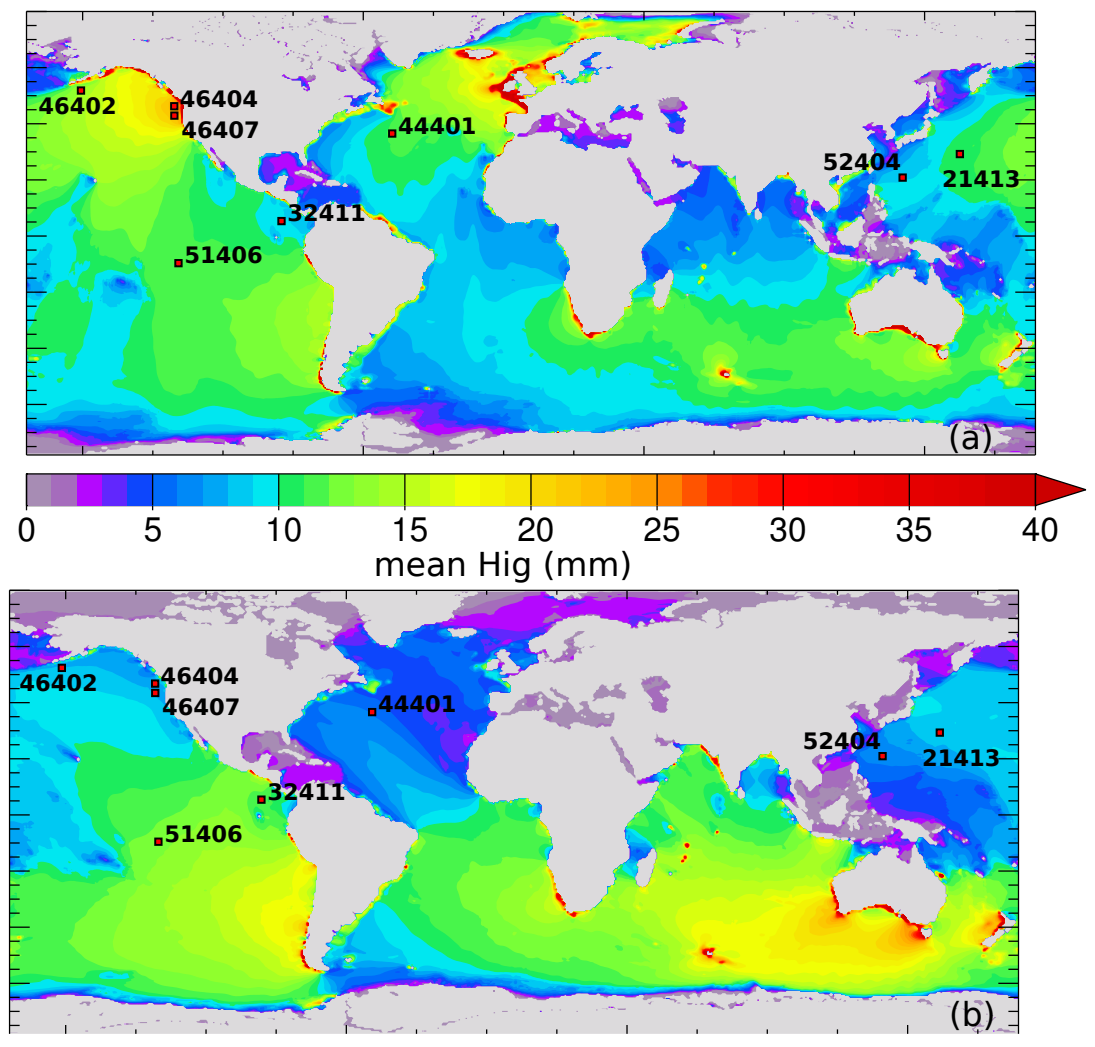

Figure 6: Mean values of $H_{I G}$ over (a) January and February 2008, (b) June and July 2008. Small square with numbers correspond to the location of DART stations used here for model validation.

ized source regions which radiate across the oceans. For the Pacific, these 
sources are the three regions identified by Webb et al. (1991), the Gulf of Alaska, Pacific North-West and southern Chile. In the case of the Indian ocean, this role is played by the Kerguelen islands and the West coast of Australia.

In each ocean basin, the IG wave field is marked by a strong temporal variability dominated by the arrival of heavy storms in coastal areas which result in bursts of free IG energy radiated from these shorelines. The resulting IG wave energy levels are generally coherent across entire ocean basins.

Figure 7 shows typical time series of IG wave heights observed and modelled. The time time series off Oregon (DART station 46407) and south of the Aleutian islands (station 46402) have many common peaks, which correspond to the same generation events. One of the strongest events in 2008, indicated by arrows, arrives on January 5 at 46407, and on January 6 at 46402. Some events recorded at DART stations in the West Pacific can be traced to sources on the Oregon or Gulf of Alaska coasts. This will be analysed in more detail elsewhere (Rawat et al., manuscript in preparation).

The model performs best off Oregon, and correlations are not so high off Alaska (station 46402), or in the Atlantic (station 44401, figure 7.c), with several recorded peaks badly underestimated in the model. These errors may be a side effect of our constant empirical factor, and will require further investigations.

In the tropical Pacific, such as at buoy 32411 off Panama, the high IG energy events have a longer duration, due to their association with swells that disperse from remote storms over several days (fig. 7.d). These events are strongly underestimated. This is not so much the case in summer, presumably because the swell sources are not so distant and swell evolution for those cases is better represented in the model.

\subsection{Frequency spectra}

We have verified that for the datasets available to us, the modelled variation of the IG wave energy across frequencies generally corresponds to measurements. This frequency dependence is controlled in part by the frequency dependence of the free IG source at the shorelines, given by eq. 6, and in the other part by the propagation effects which strongly trap the lower frequency components. Our modelled spectra are a bit too high at the lowest frequencies on the North Carolina shelf, but they are fairly accurate for the North-East Pacific, as illustrated in figure 8.a with the mean spectral shape at the DART station 46407, off the Oregon shelf. The agreement between 

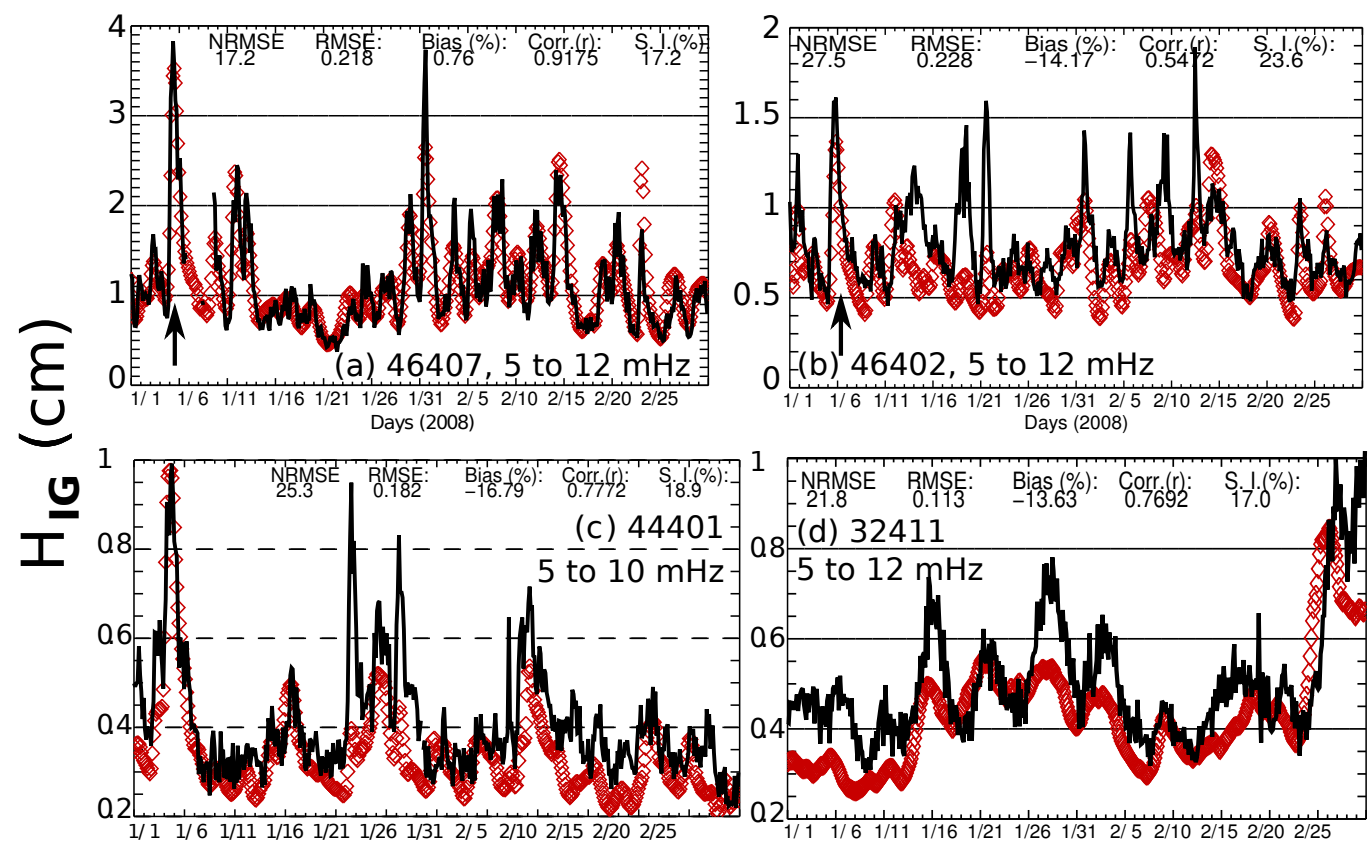

Figure 7: Representative examples of time series of $H_{I G}$ for a few selected DART stations, for the month of January and February 2008. Here $H_{I G}$ was computed from only a limited part of the IG spectrum as the higher frequencies are not always measured reliably due to their strong attenuation over the water column. See figure 6 for the instrument locations.

model and data is acceptable up to $14 \mathrm{mHz}$. Above that frequency, the measurement noise is comparable or larger than the IG signal, which cannot be recovered. For example, at station 46402, the high frequency pressure spectra is stable near $10^{-5} \mathrm{~m}^{2} / \mathrm{Hz}$ and $5 \times 10^{-6} \mathrm{~m}^{2} / \mathrm{Hz}$ at 44401 . These values are plausible estimates of the measurement noise floor, which we may assume constant across frequencies. The accuracy of the spectra of the Sea-Bird bottom pressure recorders (model SBE53) used in DART stations is limited by the measurement resolution of $0.3 \mathrm{~mm}$, which is much larger than for differential pressure gauges used by Webb et al. (1991) and many others, including Godin et al. (2013). Clearly, the spectra estimated at relatively quiet sites, such as 44401 are not reliable above $8 \mathrm{mHz}$ or so, a frequency at which noise contribution is probably larger than $30 \%$ of the measured level.

Other infragravity wave data reported by Bécel et al. (2011) also show an increase in IG levels with a possible peak around $20 \mathrm{mHz}$ in $1109 \mathrm{~m}$, and 
Crawford et al. (2005) have a peak around $15 \mathrm{mHz}$ in $900 \mathrm{~m}$ depth. The only published data that does not exhibit a rise in energy level between 5 and $10 \mathrm{mHz}$ is the New Zealand data reported by Godin et al. (2013). A specific analysis of IG waves in that region will be necessary to understand this difference. From these measurements and on our coastal validation in the previous section, we estimate that our modelled spectral shapes are probably acceptable, even for frequencies above $14 \mathrm{mHz}$ in deep water.

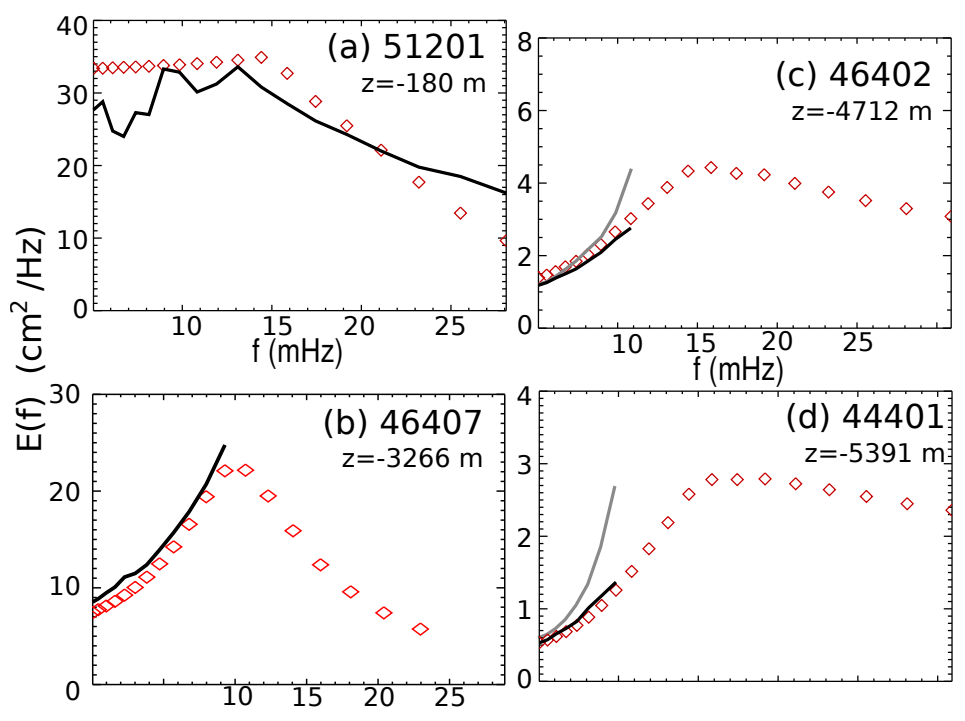

Figure 8: Measured and modelled mean spectral shapes at the station (a) 51201 off Oahu, (b) 46407, off Oregon, (c) 46402, off Alaska, (d) 44401 off Bermuda, from January to July 2008. For each station the pressure gauge noise level is estimated from the high frequency asymptote, and the measured spectrum is only shown for frequencies at which the mean spectrum is above this noise level. For 46402 and 44401, the original surface elevation spectrum converted from bottom pressure is shown in grey, and overlaid in black is an estimate of the elevation spectrum after removing the measurement noise, estimated from the high frequency noise floor.

\subsection{Frequency-time evolutions}

The time evolution of spectra close to the U.S. West Coast is characterized by a strong coherence of the energy levels at all frequencies, corresponding to the arrival of energy from nearby sources. It is only when looking at stations across the Pacific that the dispersive arrival of IG energy can be observed, although the measured level are not very high above the instrument 
noise floor. Figure 9 shows the succession of three events at the station 21413, located south-east of Japan. The most energetic event on January 5 to 7, has a maximum energy that arrives almost at the same time for frequencies between 5 at $7 \mathrm{mHz}$, and with a delay of about a day for $10 \mathrm{mHz}$. This is consistent with a burst of energy arriving from the U.S. West Coast, with little dispersion for frequencies less than $7 \mathrm{mHz}$, as these waves are in intermediate water depth $(k D=0.84$ for $f=5 \mathrm{mHz}$ and $D=5.5 \mathrm{~km})$. For higher frequencies, the modelled slope of $8 \mathrm{mHz}$ per day for the peak frequency $f_{p}$ when $f_{p}>10 \mathrm{mHz}$, is consistent with the measurements between 8 and $10 \mathrm{mHz}$, and corresponds to deep water propagation from a source located at $8000 \mathrm{~km}$ (Munk et al., 1963), which is a good approximation of the distance from the Oregon coast where the modelled source is located.

\section{Relevance of infragravity waves for satellite altimetry}

\subsection{Two-dimensional elevation patterns}

Figure 10.a shows a typical wavenumber spectrum which corresponds to a median value of the direction-integrated spectrum at $k=0.1$ cycle per kilometre (cpm) at station 46404. The energy is distributed over a wide range of directions from the East because of the distribution of IG sources all along the not-too-distance shoreline of North America to the East, with a additional narrow peak caused by IG waves coming from the North-West, corresponding to more distant shores in the Gulf of Alaska. Both spectra in fig. 10.a and 10.b yield the same direction-integrated spectrum $E(k)$. However, the shape of the sea surface elevation is clearly influenced by the directional distribution.

Given the modelled frequency-direction spectrum, we can compute a sea surface elevation map that is statistically consistent with the real sea surface. Drawing random phases for each discrete spectral component, we compute their equivalent amplitude

$$
a_{i, j}=\sqrt{2 E(f, \theta) \mathrm{d} f_{i} \mathrm{~d} \theta_{j}}
$$

and the surface is obtained by summing cosine waves with these amplitude and the chosen random phases. In practice, any measurement device will introduce a spatial averaging, and the observable pattern of sea surface elevation induced by surface waves will strongly depend on that averaging. 

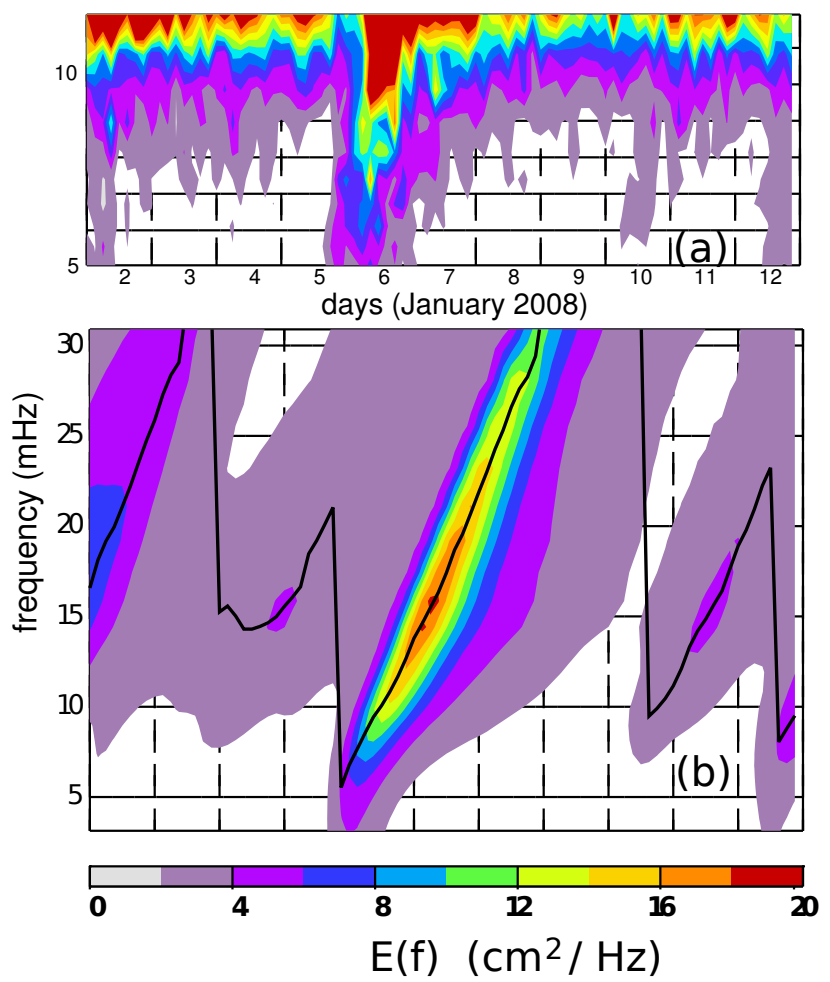

Figure 9: Evolution of IG wave spectrum at the location of DART station 21413. (a) measured and (b) modelled, with the peak period indicated by the solid line. In (a) we have not attempted to subtract the noise floor which is estimated to be $10^{-5} \mathrm{~m}^{2} / \mathrm{Hz}$ in the pressure spectrum, giving, for the surface elevation $2.5 \mathrm{~cm}^{2} / \mathrm{Hz}$ at $10 \mathrm{mHz}$ and $15 \mathrm{~cm}^{2} / \mathrm{Hz}$ at $12 \mathrm{mHz}$.

Figure 11, gives examples of surface elevations that correspond to the directional spectrum shown in fig. 10.a, with different scales of filtering. We note that if the $2 \mathrm{D}$ surface is smoothed at a 1 by $1 \mathrm{~km}$ scale, the elevation is still dominated by swells, and the IG waves are only visible when smoothing over an area 5 by $5 \mathrm{~km}$ or larger.

\subsection{Along-track wavenumber spectra}

Because most of the discussion of altimeter errors is based on today's along-track measurements, it may be relevant to compare the expected contribution of IG waves to along-track spectra. From modelled wave spectra with energy distributions computed as a function of frequency and direc- 

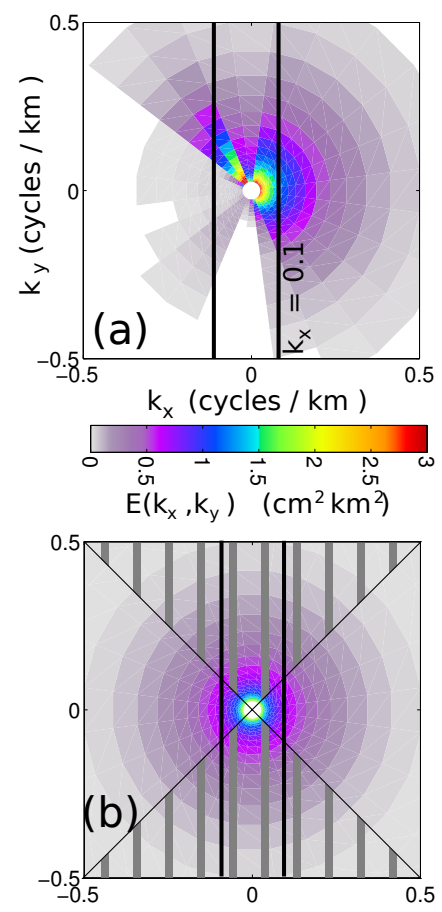

Figure 10: (a) Example of a modelled spectrum at DART station number 46404 in $2700 \mathrm{~m}$ depth, corresponding to the median spectral level $E(k)$ at a wavelength of $15 \mathrm{~km}$, and (b) isotropic spectrum with the same direction-integrated spectrum $E(k)$. An spectrum along the $x$ direction correspond to the sum over $k_{y}$. For example, the contribution at $10 \mathrm{~km}$ wavelength is given by the sum along the black solid lines at $k_{x}= \pm 0.1$ cycle per $\mathrm{km}$. The region with vertical grey hatches correspond to $\left|k_{y}\right|>\left|k_{x}\right|$.

tion, such as the one showed in figure 10.a, we may estimate the spectra in wavenumber space (e.g Komen et al., 1994),

$$
E(k)=\frac{\mathrm{d} f}{\mathrm{~d} k} E(f)=\frac{C_{g}}{2 \pi} E(f)=\frac{C_{g}}{2 \pi} \int_{0}^{2 \pi} E(f, \theta),
$$

where $C_{g}$ is the group speed of linear waves, as given by Airy wave theory. In order to simplify our discussion we assume here that the IG wave spectrum is isotropic, as shown in figure 10.b, and thus the two-dimensional spectrum in wave-vector space $\left(k_{x}, k_{y}\right)$ or wavenumber and direction thus can be computed as follows,

$$
E(k, \theta)=\frac{E(k)}{2 \pi}=E(f) \frac{C_{g}}{4 \pi^{2}}
$$




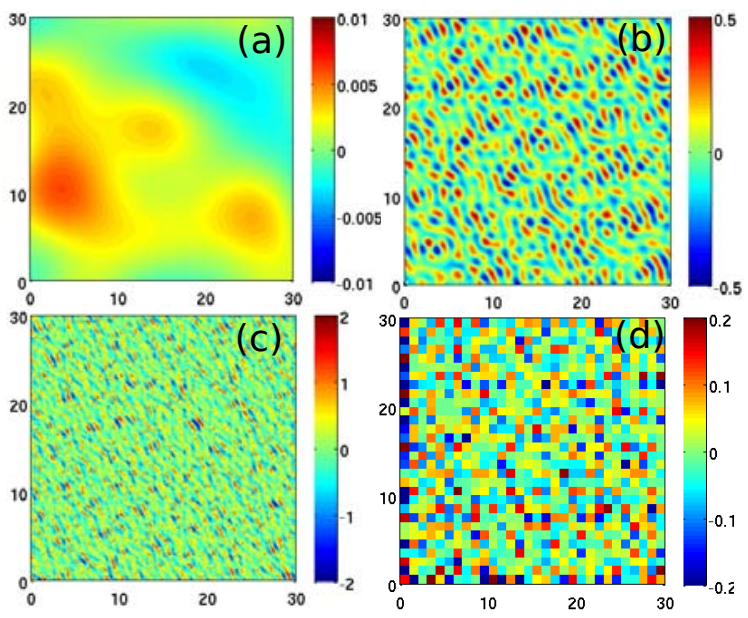

Figure 11: Sea surface elevation maps, in meters, filtered at different scales. All maps are obtained from the spectrum shown in figure 10.a by summing spectral components with random phases, taking into account components longer than (a) $11 \mathrm{~km}$, (b) $240 \mathrm{~m}$, (c) and (d) $36 \mathrm{~m}$. The surface is first computed at $10 \mathrm{~m}$ resolution and then averaged at $100 \mathrm{~m}$ resolution or (d) $1 \mathrm{~km}$ resolution. Please note the different elevation scales, all in meters, from $1 \mathrm{~cm}$ in (a) to $2 \mathrm{~m}$ in (c).

$$
E\left(k_{x}, k_{y}\right)=E(k, \theta) / k=E(f) \frac{C_{g}}{k 4 \pi^{2}} .
$$

From this we can obtain the spectrum along one direction, say $x$, by integrating along the other dimension, $y$,

$$
E\left(k_{x}\right)=\int_{-\infty}^{\infty} E\left(k_{x}, k_{y}\right) \mathrm{d} k_{y},
$$

which is a double-sided spectrum with values for both $k_{x}<0$ and $k_{x}>0$. In practice, we will instead use single-sided spectrum, thereby correcting the factor 2 underestimation in Aucan and Ardhuin (2013),

$$
E\left(k_{x}\right)=2 \int_{-\infty}^{\infty} E\left(k_{x}, k_{y}\right) \mathrm{d} k_{y} .
$$

Because eq. 15 is an integral over $k_{y}$, it includes the contributions of wave components that are actually much shorter than $k_{x}$. For our applications, the wind seas and swell contribute a very large value to $E\left(k_{x}\right)$, leading to values 
of the order of $100 \mathrm{~cm}^{2} /(\mathrm{cycle} / \mathrm{km})$. Such a spectral density corresponds to the spectrum of the elevation signal recorded along an infinitely thin swath.

In practice, all altimeters launched so far have a cross-track footprint width of the order of $6 \mathrm{~km}$, and SWOT will have a cross-track resolution of the order of $500 \mathrm{~m}$ over the oceans. The along-track resolutions can be different for altimeters processed in delay-Doppler mode such as Cryosat-2 SARM mode. For illustration purposes we have chosen to average over $7.5 \mathrm{~km}$ in the across-track direction. This choice is fairly arbitrary but happens to coincide with the averaging chosen for defining instrument errors in the SWOT Science Requirement Document (Second release, version 1.1, available from Jet Propulsion Laboratory).

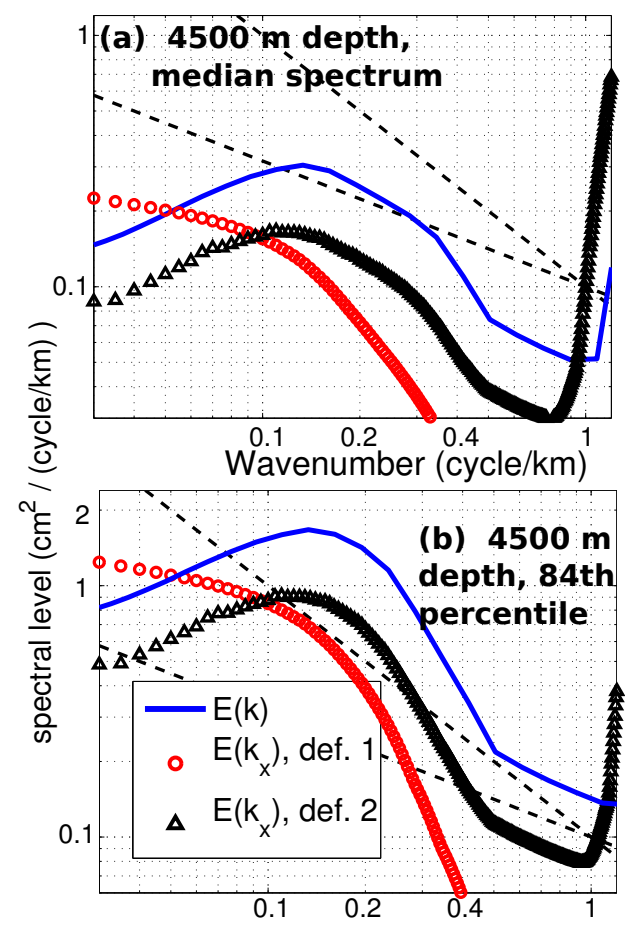

Figure 12: Modelled spectra at the location of the Gascogne buoy, in the Bay of Biscay, for the year 2008, corresponding to (a) the median and (b) the 84th percentile See figure 14 for symbols. A 7-km cross-track average (def. 1) gives a very different shape than an average over wavenumbers higher than $k_{x}$ (def. 2). 
Taking into account the cross-track averaging gives

$$
\widehat{E}\left(k_{x}\right)=2 \int_{-\infty}^{\infty} \widehat{E}\left(k_{x}, k_{y}\right) \mathrm{d} k_{y}
$$

where $\widehat{E}\left(k_{x}, k_{y}\right)$ is the surface elevation spectrum convoluted by the instrument observation processing. A cross-track average over $7.5 \mathrm{~km}$ would give approximately $\widehat{E}=E$ for $\left|k_{y}\right|<0.13$ cycle $/ \mathrm{km}$ and $\widehat{E}=0$ otherwise. In practice we have used a Hann window with a full width of $7.5 \mathrm{~km}$, hence a shorter effective width. If one wanted to know the spectral level at any scale $k_{x}$ without interference from shorter oblique components with larger values of $k_{y}$, the solution is probably to remove components with $\left|k_{y}\right|>\left|k_{x}\right|$ (hatched region in figure 10.b). In that case, the spectra only retain components that have wavelengths between $1 / k_{x}$ and $1 /\left(\sqrt{2} k_{x}\right)$, excluding the much shorter components that would have come for very large values of $k_{y}$. These two estimates of $\widehat{E}\left(k_{x}\right)$ are illustrated in figure 12 for the median and 84th percentile at a deep water location. The two estimates of $\widehat{E}\left(k_{x}\right)$ typically fall between $E(k) / 2$ and $E(k)$, of the order of $1 \mathrm{~cm}^{2} /($ cycle $/ \mathrm{km})$, for wavelengths between 5 and $10 \mathrm{~km}$, which roughly corresponds to the peak of the free IG wave spectrum. The variability of the along-track spectrum is thus largely associated to changes in the direction-integrated spectrum $E(k)$, which is very variable for wavelengths longer than $50 \mathrm{~m}$, as shown on figure 13.

Although the frequency spectrum $E(f)$ increases towards shallow water as detailed in section 2, the waves become shorter and the change in energy level at a fixed wavenumber is not obvious and depends on the shape of the free IG spectrum. For water depths less than $300 \mathrm{~m}$, wavelengths larger than $10 \mathrm{~km}$ correspond to periods longer than $200 \mathrm{~s}$, which have not been estimated here but which could be extrapolated from the DART station data and our model results.

\section{Summary and perspectives}

We have demonstrated the capability of spectral wave models to reproduce the variability of infragravity (IG) wave energy in a wide range of environments. This confirms the analyses by Webb et al. (1991) and Filloux et al. (1991) that bottom pressure records in the frequency band from 5 to $14 \mathrm{mHz}$ are dominated by free IG waves radiated from shorelines. For 


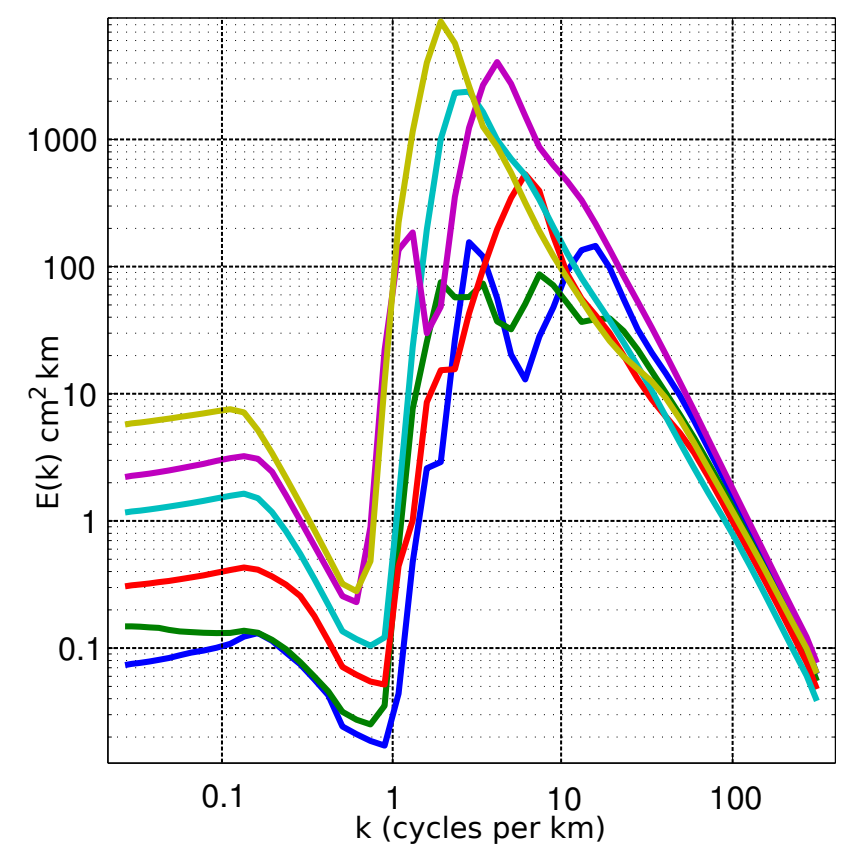

Figure 13: Modelled spectra at DART station 46404, off the U.S. Pacific Northwest, corresponding to the 5th, 15th, 50th (median), 84th, 95th and 99th percentile at $10 \mathrm{~km}$ wavelength, for the year 2008.

higher IG wave frequencies, we have at present no validation for the energy levels in the open ocean, but the model is consistent with bottom pressure records in shallower water.

Validity of the present model is still uncertain in regions where no data are available, because of our use of an empirical proportionality factor $\alpha_{1}$ between the parameterized free IG source at the shoreline, and the wind sea and swell parameters. We have found that $\alpha_{1}$ could vary by a factor 2 between different coastal sites. Also, the shape of spectra of free IG sources has been prescribed here, but it should probably be a function of the waves arriving at the shoreline and possibly of the nearshore bathymetry. Finally, the numerical procedure used here introduces a discontinuity between an infragravity wave band in which the waves arriving at the coast are absorbed, and the main swell and wind sea band, in which free IG energy is added to the incoming and reflected waves. Ideally, this special treatment of the IG band should be removed and a free IG source function should be defined 


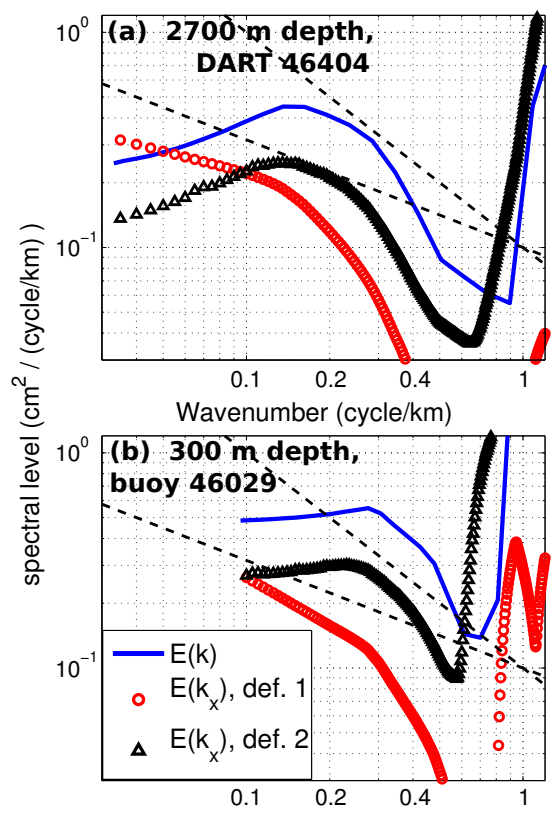

Figure 14: Modelled median spectra at two locations off the U.S. Pacific Northwest: (a) in $3700 \mathrm{~m}$ depth, (b) in $300 \mathrm{~m}$ depth. The solid line is the spectrum $E(k)$ corresponding to the median modelled spectral density for a wavelength of $10 \mathrm{~km}$. Circles and triangles are spectral densities $E\left(k_{x}\right)$ along direction $x$, assuming an isotropic spectrum, with two possible definitions of the averaging in the other direction $y$. With definition 1 , we applied a Hann window with a full width of $7.5 \mathrm{~km}$ in the $y$ direction, giving a spectrum with first zeros at $k_{y}= \pm 0.26$ cycle $/ \mathrm{km}$. With definition 2, spectral components with $\left|k_{y}\right|>\left|k_{x}\right|$ are set to zero. The two dashed line show spectral slopes of $k^{-1}$ and $k^{-1 / 2}$. A 7 -km crosstrack average (def. 1) gives a very different shape than an average over wavenumbers higher than $k_{x}$ (def. 2).

instead of a target equilibrium spectrum. Parameterizations related to first principles and the known evolution of waves in shallow water will be needed to overcome these difficulties and build confidence in model estimates. More data will be needed to further validate the model in regions of the world where it has not been tested and for wave periods that were not accessible to bottom pressure recorders.

In the context of the SWOT altimetry mission, for which the required instrument error on the sea surface elevation spectrum is less than $2 \mathrm{~cm}^{2} /($ cycle / km) for wavelengths less than $20 \mathrm{~km}$, we anticipate that free IG waves will often be an important additional source of geophysical error when convert- 
ing elevations into surface currents, especially off the west coasts of North America and Europe, and for wavelengths around $10 \mathrm{~km}$. The magnitude of that error can be predicted using the model presented here, and the altimeter data processing can probably be optimized to minimize its impact.

\section{Appendix A. Propagation of free infragravity waves in a spectral wave model}

Because we solve for the wave energy propagation using the standard finite-difference and residual distribution schemes of the WW3 model (Tolman, 2002b; Roland, 2008), using a relatively coarse directional discretization with 24 directions, we need to verify that the free IG wave energy actually decays properly from the shallow to the deep ocean. In practice, there are two important sources of error in the propagation, the first is associated to the 'splitting error', namely the fact that refraction and advection are integrated separately with sub-time steps DTS within a larger global time step DTG. The other source of error is the refraction limiter, which limits the turning of wave energy to one direction bin within one time step. This limiter may lead to an overestimation of the IG energy leakage to the open ocean.

For that latter reason, it is preferable not to use too many directions in the spectral discretization, because it would otherwise lead to small refraction steps DTS, and, in order to limit the splitting error, a small DTG also. We have tested the importance of these errors with a simplified along-shore uniform topography that represents a realistic transition from a shelf to an abyssal plain.

The use of 24 or 36 directions only in the model discretization has another drawback. Because the free IG sources tend to be fixed in the same position, a 'garden sprinkler effect' (GSE) (SWAMP Group, 1984; Booij and Holthuijsen, 1987) is clearly visible in our global ocean calculations, with higher energy

along the directions of discretization. The contrast between the energy in the discrete and in-between directions can be as high as a factor of two for the most compact IG sources, such as the Kerguelen islands. It is still visible in monthly means such as figure 6 . This contrast should be equal to one in a perfect model. Higher directional resolution or alternatives to the GSE alleviation routine used here, already proposed by Tolman (2002a) will be tested in future evolutions of the model in order to reduce this spurious contrast.

Acknowledgments. This work would not have been possible without the bottom pressure data collected by SIO crews, under the supervision of T.H.C. 
Herbers, and NGDC efforts to maintain the DART network. Bottom Pressure and surface wave data in Waimea Bay, Hawaii, were collected by the group of Mark Merrifield, at the University of Hawaii. F.A. is funded by ERC grant \#240009 "IOWAGA" and U.S. National Ocean Partnership Program, under grant N00014-10-1-0383. Specific developments for infragravity waves are funded by CNES as part of the SWOT preparation program and Labex Mer under grant ANR-10-LABX-19-01. Comments by anonymous reviewers led to significant improvements in the manuscript.

\section{References}

Ardhuin, F., Drake, T. G., Herbers, T. H. C., 2002. Observations of wavegenerated vortex ripples on the North Carolina continental shelf. J. Geophys. Res. 107 (C10), dOI:10.1029/2001JC000986.

Ardhuin, F., Herbers, T. H. C., Jessen, P. F., O’Reilly, W. C., 2003a. Swell transformation across the continental shelf. part II: validation of a spectral energy balance equation. J. Phys. Oceanogr. 33, 1940-1953.

URL http://tinyurl.com/3aauzjq

Ardhuin, F., Herbers, T. H. C., O’Reilly, W. C., 2001. A hybrid EulerianLagrangian model for spectral wave evolution with application to bottom friction on the continental shelf. J. Phys. Oceanogr. 31 (6), 1498-1516.

Ardhuin, F., Herbers, T. H. C., Watts, K. P., van Vledder, G. P., Jensen, R., Graber, H., 2007. Swell and slanting fetch effects on wind wave growth. J. Phys. Oceanogr. 37 (4), 908-931.

Ardhuin, F., Lavanant, T., Obrebski, M., Marié, L., Royer, J.-Y., d'Eu, J.F., Howe, B. M., Lukas, R., Aucan, J., 2013. A numerical model for ocean ultra low frequency noise: wave-generated acoustic-gravity and Rayleigh modes. J. Acoust. Soc. Amer. 134 (4), 3242-3259.

Ardhuin, F., O’Reilly, W. C., Herbers, T. H. C., Jessen, P. F., 2003b. Swell transformation across the continental shelf. part I: Attenuation and directional broadening. J. Phys. Oceanogr. 33, 1921-1939. URL http://journals.ametsoc.org/doi/pdf/10.1175/1520-0485\%282003\%29033\%3C1921\%3 
Ardhuin, F., Pineau-Guillou, L., Fichaut, B., Suanez, S., Corman, D., Filipot, J.-F., 2011a. Extreme set-up and run-up on steep cliffs (Banneg Island, France). In: Proceedings, 12th Int. Workshop of Wave Hindcasting and Forecasting, Hawaii.

Ardhuin, F., Rogers, E., Babanin, A., Filipot, J.-F., Magne, R., Roland, A., van der Westhuysen, A., Queffeulou, P., Lefevre, J.-M., Aouf, L., Collard, F., 2010. Semi-empirical dissipation source functions for wind-wave models: part I, definition, calibration and validation. J. Phys. Oceanogr. 40 (9), $1917-1941$.

Ardhuin, F., Roland, A., 2012. Coastal wave reflection, directional spreading, and seismo-acoustic noise sources. J. Geophys. Res. 117, C00J20.

Ardhuin, F., Tournadre, J., Queffelou, P., Girard-Ardhuin, F., 2011b. Observation and parameterization of small icebergs: drifting breakwaters in the southern ocean. Ocean Modelling 39, 405-410.

Aucan, J., Ardhuin, F., 2013. Infragravity waves in the deep ocean : An upward revision. Geophys. Res. Lett. 40, 1-5.

Bécel, A., Laigle, M., Diaz, J., Montagner, J.-P., Hirn, A., 2011. Earth's free oscillations recorded by free-fall obs ocean-bottom seismometers at the lesser antilles subduction zone. Geophys. Res. Lett. 38, L24305.

Biesel, F., 1952. Equations générales au second ordre de la houle irrégulière. Houille Blanche 5, 372-376.

Booij, N., Holthuijsen, L. H., 1987. Propagation of ocean waves in discrete spectral wave models. J. Comp. Phys. 68, 307-326.

Crawford, W. C., Singh, S. C., Hulme, T., Smallwood, J. R., 2005. Applications of seafloor compliance measurements in the faroes-shetland basin. Annales Societatis Scientiarum Faeroensis, Supplementum 43, 32-43.

Creamer, D. B., Henyey, F., Schult, R., Wright, J., 1989. Improved linear representation of ocean surface waves. J. Fluid Mech. 205, 135-161.

Csík, Á., Ricchiuto, M., Deconinck, H., 2002. A conservative formulation of the multidimensional upwind residual distribution schemes for general nonlinear conservation laws. J. Comp. Phys. 172 (2), 286-312. 
de Jong, M. P. C., Holthuijsen, L. H., Battjes, J. A., 2003. Generation of seiches by cold fronts over the southern north sea. J. Geophys. Res. 108 (C4), 3117, doi:10.1029/2002JC001422.

de Laplace, P. S., 1776. Suite des recherches sur plusieurs points du système du monde (XXV-XXVII). Mém. Présentés Acad. R. Sci. Inst. France, 542552 .

Durand, M., Fu, L.-L., Lettenmaier, D., Alsdorf, D., Rodriguez, E., EstebanFernandez, D., 2010. The surface water and ocean topography mission: Observing terrestrial surface water and oceanic submesoscale eddies. Proc. IEEE 98 (5), 766-779.

Evangelidis, D. A., Jun. 1996. Infragravity waves on the continental shelf. Master's thesis, Naval Postgraduate School, Monterey, CA.

Fichaut, B., Suanez, S., 2011. Quarrying, transport and deposition of clifftop storm deposits during extreme events: Banneg island. Marine Geology $283,36-55$.

Filloux, J. H., 1980. Pressure fluctuations on the open ocean floor over a broad frequency range: new program and early results. J. Phys. Oceanogr. 10, 1959-1971.

Filloux, J. H., Luther, D. S., Chave, A. D., 1991. Long-term sea floor measurements of water pressure: Normal modesand infragravity waves. In: Proceedings of the 20th General Assembly, IUGG, Vienna, Austria, 11-24 August. p. 6 pp. and 11 figures.

Godin, O. A., Zabotin, N. A., Sheehan, A. F., Yang, Z., Collins, J. A., 2013. Power spectra of infragravity waves in a deep ocean. Geophys. Res. Lett. 40, 2159-2165.

Grant, W. D., Madsen, O. S., 1979. Combined wave and current interaction with a rough bottom. J. Geophys. Res. 84, 1797-1808.

Guyonic, S., Mory, M., Wever, T. F., Ardhuin, F., Garlan, T., 2007. Full-scale mine burial experiments in wave and current environments and comparison with models. IEEE J. Oceanic Eng. 32 (1), 119-132. 
Henderson, S. M., Bowen, A. J., 2002. Observations of surf beat forcing and dissipation. J. Geophys. Res. 107 (C11), 3193.

Herbers, T. H. C., Burton, M. C., 1997. Nonlinear shoaling of directionally spread waves on a beach. J. Geophys. Res. 102 (C9), 21,101-21,114.

Herbers, T. H. C., Elgar, S., Guza, R. T., 1994. Infragravity-frequency (0.005-0.05 Hz) motions on the shelf, part I, forced waves. J. Phys. Oceanogr. 24, 917-927.

URL http://journals.ametsoc.org/doi/pdf/10.1175/1520-0485\%281994\%29024\%3C0917\%3

Herbers, T. H. C., Elgar, S., Guza, R. T., 1995a. Generation and propagation of infragravity waves. J. Geophys. Res. 100 (C2), 24863-24872.

Herbers, T. H. C., Elgar, S., Guza, R. T., 1995b. Infragravity-frequency $(0.005-0.05 \mathrm{~Hz})$ motions on the shelf. part II: free waves. J. Phys. Oceanogr. 25, 1063-1079.

URL http://journals.ametsoc.org/doi/pdf/10.1175/1520-0485\%281995\%29025\%3C1063\%3

Herbers, T. H. C., Elgar, S., Guza, R. T., 1999. Directional spreading of waves in the nearshore. J. Geophys. Res. 104 (C4), 7683-7693.

Herbers, T. H. C., Lowe, R. L., Guza, R. T., 1992. Field observations of orbital velocities and pressure in weakly nonlinear surface gravity waves. J. Fluid Mech. 245, 413-435.

Herbers, T. H. C., Russnogle, N. R., Elgar, S., 2000. Spectral energy balance of breaking waves within the surf zone. J. Phys. Oceanogr. 30 (11), $2723-2737$.

URL http://journals.ametsoc.org/doi/pdf/10.1175/1520-0485\%282000\%29030\%3C2723\%3

Janssen, P. A. E. M., 2009. On some consequences of the canonical transformation in the Hamiltonian theory of water waves. J. Fluid Mech. 637, $1-44$.

Kahma, K. K., Calkoen, C. J., 1992. Reconciling discrepancies in the observed growth of wind-generated waves. J. Phys. Oceanogr. 22, 1389-1405.

URL http://journals.ametsoc.org/doi/pdf/10.1175/1520-0485\%281992\%29022\%3C1389\%3

Klein, P., Isern-Fontanet, J., Lapeyre, G., Roullet, G., Danioux, E., Chapron, B., Le Gentil, S., Sasaki, H., 2009. Diagnosis of vertical velocities in the 
upper ocean from high resolution sea surface height. Geophys. Res. Lett. 36, L12603.

Komen, G. J., Cavaleri, L., Donelan, M., Hasselmann, K., Hasselmann, S., Janssen, P. A. E. M., 1994. Dynamics and modelling of ocean waves. Cambridge University Press, Cambridge.

Lapeyre, G., Klein, P., 2006. Dynamics of the upper oceanic layers in terms of surface quasigeostrophy theory. J. Phys. Oceanogr. 36, 165-176.

Le Traon, P.-Y., Klein, P., Hua, B. L., Dibarboure, G., 2008. Do altimeter wavenumber spectra agree with the interior or surface quasigeostrophic theory? J. Phys. Oceanogr. 38, 1137-1142.

Leonard, B. P., 1991. The ULTIMATE conservative difference scheme applied to unsteady one-dimensional advection. Computational Methods in Applied Mechanical Engineering 88, 17-74.

Longuet-Higgins, M. S., 1957. On the transformation of a continuous spectrum by refraction. Proceedings of the Cambridge philosophical society 53 (1), 226-229.

Lygre, A., Krogstad, H. E., 1986. Maximum entropy estimation of the directional distribution in ocean wave spectra. J. Phys. Oceanogr. 16, 2,0522,060 .

Magne, R., Belibassakis, K., Herbers, T. H. C., Ardhuin, F., O’Reilly, W. C., Rey, V., 2007. Evolution of surface gravity waves over a submarine canyon. J. Geophys. Res. 112, C01002.

Munk, W. H., 1949. Surf beat. Eos Trans. AGU 30, 849-854.

Munk, W. H., Miller, G. R., Snodgrass, F. E., Barber, N. F., 1963. Directional recording of swell from distant storms. Phil. Trans. Roy. Soc. London A $255,505-584$.

Okihiro, M., Guza, R. T., Seymour, R. J., 1993. Excitation of seiche observed in a small harbor. J. Geophys. Res. 98 (C10), 18201-18211.

Rascle, N., Ardhuin, F., 2013. A global wave parameter database for geophysical applications. part 2: model validation with improved source term parameterization. Ocean Modelling 70, 174-188. 
Reniers, A. J. H. M., Groenewegen, M. J., Ewans, K. C., Masterton, S., Stelling, G. S., Meek, J., 2010. Estimation of infragravity waves at intermediate water depth. Coastal Eng. 57, 52-61.

Reniers, A. J. H. M., van Dongeren, A. R., Battjes, J. A., Thornton, E. B., 2002. Linear modeling of infragravity waves during delilah. J. Geophys. Res. 107 (C10), 3137.

Rhie, J., Romanowicz, B., 2006. A study of the relation between ocean storms and the Earth-s hum. Geochemistry Geophysics Geosystems 7 (10), Q10004.

Roland, A., 2008. Development of WWM II: Spectral wave modelling on unstructured meshes. Ph.D. thesis, Technische Universität Darmstadt, Institute of Hydraulic and Water Resources Engineering.

Ruju, A., Lara, J. L., Losada, I. J., 2012. Radiation stress and low-frequency energy balance within the surf zone: A numerical approach. Coastal Eng. $68,44-55$.

Saulnier, J.-B., Clément, A., de O. Falcão, A. F., Pontes, T., Prevosto, M., Ricci, P., 2011. Wave groupiness and spectral bandwidth as relevant parameters for the performance assessment of wave energy converters. Ocean Eng. 38 (1), 130-147.

Sheremet, A., Staples, T., Ardhuin, F., Suanez, S., Fichaut, B., 2014. Observations of large infragravity-wave run-up at banneg island, france. Geophys. Res. Lett. 41.

SWAMP Group, 1984. Ocean wave modelling. Plenum Press, New York.

Symonds, G., Huntley, D. A., Bowen, A. J., 1982. Two-dimensional surf beat: Long wavegeneration by a time-varying breakpoint. J. Geophys. Res. 87, 492-498.

Thomson, J., Elgar, S., Herbers, T., 2005. Reflection and tunneling of ocean waves observed at a submarine canyon. Geophys. Res. Lett. 32, L10602.

Toledo, Y., Agnon, Y., 2012. Stochastic evolution equations with localized nonlinear shoaling coefficients. Eur. J. Mech. B/Fluids 34, 13-18. 
Tolman, H. L., 2002a. Alleviating the garden sprinkler effect in wind wave models. Ocean Modelling 4, 269-289.

Tolman, H. L., 2002b. Distributed memory concepts in the wave model WAVEWATCH III. Parallel Computing 28, 35-52.

Tolman, H. L., 2008. A mosaic approach to wind wave modeling. Ocean Modelling 25, 35-47.

Tournadre, J., Girard-Ardhuin, F., Legrésy, B., 2012. Antarctic iceberg distributions 2002-2010. J. Geophys. Res. 117 (7), C05004.

Tucker, M., 1950. Surf beats: sea waves of 1 to 5 min. period. Proc. Roy. Soc. Lond. A 202, 565-573.

Webb, S., Zhang, X., Crawford, W., 1991. Infragravity waves in the deep ocean. J. Geophys. Res. 96, 2723-2736.

Young, I., 1995. The determination of confidence limits associated with estimates of the spectral peak frequency. Ocean Eng. 22, 669-686.

Zijlema, M., Stelling, G., Smit, P., 2011. SWASH: An operational public domain code for simulating wave fields and rapidly varied flows in coastal waters. Coastal Eng. 58, 992-1012. 

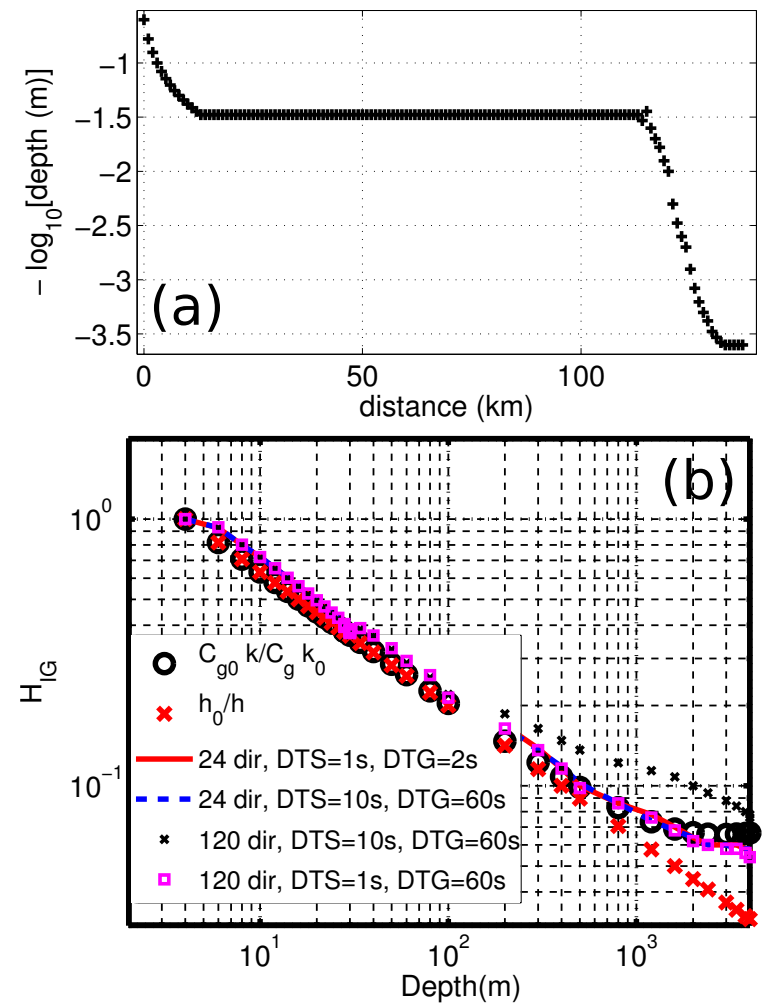

Figure A.1: Verification of the WW3 numerical scheme for IG wave propagation from a shelf to an abyssal plain, using an alongshore-uniform topography. (a) Depth profile and (b) infragravity wave height obtained with different refraction time steps (DTS) and directional discretizations (24 or 120 directions). The theoretical decay of the IG wave height using a WKB approximation and a broad direction distribution is proportional to $1 / h$ in shallow water (Herbers et al., 1995b) and $k / C_{g}$ in general. 